\title{
NKCC1 controls GABAergic signaling and neuroblast migration in the postnatal forebrain
}

Sheyla Mejia-Gervacio ${ }^{1,2^{*}}$, Kerren Murray ${ }^{1,2}$, Pierre-Marie Lledo ${ }^{1,2^{*}}$

\begin{abstract}
From an early postnatal period and throughout life there is a continuous production of olfactory bulb (OB) interneurons originating from neuronal precursors in the subventricular zone. To reach the OB circuits, immature neuroblasts migrate along the rostral migratory stream (RMS). In the present study, we employed cultured postnatal mouse forebrain slices and used lentiviral vectors to label neuronal precursors with GFP and to manipulate the expression levels of the Na-K-2Cl cotransporter NKCC1. We investigated the role of this $\mathrm{Cl}^{-}$ transporter in different stages of postnatal neurogenesis, including neuroblast migration and integration in the $\mathrm{OB}$ networks once they have reached the granule cell layer (GCL). We report that NKCC1 activity is necessary for maintaining normal migratory speed. Both pharmacological and genetic manipulations revealed that NKCC1 maintains high $\left[\mathrm{Cl}^{-}\right]_{i}$ and regulates the resting membrane potential of migratory neuroblasts whilst its functional expression is strongly reduced at the time cells reach the GCL. As in other developing systems, NKCC1 shapes $\mathrm{GABA}_{A}$-dependent signaling in the RMS neuroblasts. Also, we show that NKCC1 controls the migration of neuroblasts in the RMS. The present study indeed indicates that the latter effect results from a novel action of NKCC1 on the resting membrane potential, which is independent of $\mathrm{GABA}_{\mathrm{A}}$-dependent signaling. All in all, our findings show that early stages of the postnatal recruitment of $O B$ interneurons rely on precise, orchestrated mechanisms that depend on multiple actions of NKCC1.
\end{abstract}

\section{Background}

The subventricular zone (SVZ) and the rostral migratory stream (RMS) contain neural progenitors that proliferate and migrate to the olfactory bulb $(\mathrm{OB})$ throughout life [1]. In the $O B$, the precursors differentiate into two classes of interneurons: granule cells (GCs) and periglomerular cells (PGCs) [2-4], which populate deep and superficial layers of the $\mathrm{OB}$, respectively.

The migration of neuroblasts in the RMS is a highly regulated process, and may determine the rate of integration of newborn neurons in the OB. A series of chemical factors have been identified as regulators of neuroblast migration in the RMS, including adhesion molecules [5], extracellular matrix molecules [6], and molecules with repulsive/attractive functions [7-9]. Moreover, migration in the SVZ-OB system is sensitive to the action of neurotransmitters $[10,11]$, providing a basis for neural activity-dependent regulation of

\footnotetext{
* Correspondence: mejiashe@univ-paris5.fr; pmlledo@pasteur.fr 'Institut Pasteur, Laboratory for Perception and Memory, 25 rue du Dr. Roux, F-75724 Paris Cedex 15, France

Full list of author information is available at the end of the article
}

postnatal neurogenesis. In this regard, a previous study showed that neuroblast migration in the RMS is reduced by the tonic depolarizing action of gamma-aminobutyric acid (GABA) acting on $\mathrm{GABA}_{\mathrm{A}}$ receptors [12,13].

$\mathrm{GABA}_{\mathrm{A}}$ receptor activity affects the cell membrane potential, producing depolarizing or hyperpolarizing influences depending on the $\mathrm{Cl}^{-}$gradient across the cell membrane, principally determined by the intracellular concentration of $\mathrm{Cl}^{-}\left(\left[\mathrm{Cl}^{-}\right]_{\mathrm{i}}\right)[14-16]$. $\left[\mathrm{Cl}^{-}\right]_{\mathrm{i}}$ is tightly regulated by the activity of ionic transporters such as $\mathrm{Na}^{+}$$\mathrm{K}^{+}-2 \mathrm{Cl}^{-}(\mathrm{NKCC} 1)$ or $\mathrm{K}^{+}-\mathrm{Cl}^{-}$(KCC2) [17-19], which, following the driving force of $\mathrm{Na}^{+}$and $\mathrm{K}^{+}$, have the tendency to increase or decrease, respectively, the $\left[\mathrm{Cl}^{-}\right]_{\mathrm{i}}$ at rest.

NKCC1 is frequently expressed in developing central nervous system regions and its activity has been associated with depolarizing actions of GABA [19-23]. It is presently unknown if NKCC1 regulates the $\left[\mathrm{Cl}^{-}\right]_{\mathrm{i}}$ in the RMS. This is an important issue since, in several regions, depolarizing GABA signaling appears early in development and can modulate neuronal excitability to promote neuronal maturation [21,24-27].

\section{Ciomed Central}


In the present study, we investigated whether NKCC1 shapes the action of GABA on the maturation of $O B$ neuronal precursors and its influence on cellular motility. Our results indicate that the activation of $\mathrm{GABA}_{\mathrm{A}}$ receptors induces a strong positive driving force in migrating neuroblasts, which diminishes upon arrival of the cells at the GC layer (GCL). We identified NKCC1 as the uptake mechanism maintaining elevated $\left[\mathrm{Cl}^{-}\right]_{\mathrm{i}}$ in migrating neuroblasts, thus shaping the action of $\mathrm{GABA}_{\mathrm{A}}$ receptors. Moreover, we report that the activity of NKCC1 is necessary to maintain normal migration speed and this process occurs independently of $\mathrm{GABA}_{\mathrm{A}}$ signaling since NKCC1 controls the resting state of excitability in RMS neuroblasts.

\section{Results}

\section{Forebrain organotypic slice cultures}

We developed an organotypic slice culture model that maintains the anatomical organization of the SVZ-OB system (Figure 1A) to study the migration and the first steps of integration of neuronal precursors in the $\mathrm{OB}$ circuit at early postnatal periods. For this study, the slices were obtained from 7-day-old mice and maintained for up to 12 days in vitro (div). Immunohistochemical staining performed at 6 div with antibodies directed against a neuronal precursor marker (doublecortin (DCX); $\mathrm{n}=3$ slices; Additional file 1) and more mature neuronal markers (NeuN, tyrosine hydroxylase $(\mathrm{TH})$ and GABA; $\mathrm{n}=3$ slices for each; Additional files 1 and 2) were in agreement with the expected distribution patterns observed at similar postnatal ages, as visually compared to the Allen Institute for Brain Science atlas for P14 animals (and P7 when available) for TH and DCX. Similarly, our labeling corresponded to previously published data from adult slices for GABA in the RMS [12] and NeuN in the OB [28,29]. Together, these observations suggested that overall $\mathrm{OB}$ organization was preserved in our slice model.

A total of 132 cultured slices were transduced at 1 div with lentiviral vectors to induce the expression of GFP and to manipulate their levels of NKCC1 expression in SVZ precursor cells. After 1 to 2 days post-injection (dpi), strong GFP labeling was visible at the injection site (Figure 1A,B). Several $\mathrm{GFP}^{+}$cells were distributed along the RMS shortly after vector injection ( $>3 \mathrm{dpi}$; Figure $1 \mathrm{C}$ ). These labeled cells displayed typical morphology of migrating neuroblasts, with a small and elongated cell body (6 to $8 \mu \mathrm{m}$ ), including leading and trailing processes [30]. The first $\mathrm{GFP}^{+}$cells reached the GCL 5 days after vector injection (Figure 1D). Six days after injection, scattered cells were observed throughout the bulb, including in the glomerular layer (Figure 1E). After reaching the appropriate layer, the morphology of $\mathrm{GFP}^{+}$cells changed, with cells transforming into more mature $\mathrm{OB}$ interneurons including mainly $\mathrm{GC}$ and less numerous PGCs.

The use of lentiviral vectors precludes precise birthdating of newborn neurons. Nonetheless, from morphological and physiological points of view, the population of neuroblasts studied was homogeneous during the course of our analysis (around 10 days). We used the measurement of input membrane resistance (IR) as an index of cell maturation [31] and recorded GC in addition to RMS neuroblasts for comparison. In the RMS, we did not find a correlation between the IR and the number of dpi ( $n=15$ from 11 slices; $P=0.36$; Additional file $3 \mathrm{~A}$ ), while a significant decrease in IR over time $(P=0.05)$ was seen for $\mathrm{GFP}^{+}$cells recorded in the GCL ( $n=21$ from 19 slices; Additional file 3B), consistent with the expected maturation of newborn GCs.

\section{Efficacy of a short hairpin RNA for NKCC1}

To test the potential effects of NKCC1 on neuroblast migration and their electrophysiological properties, we used two different strategies. The first consisted of the pharmacological blockade of NKCC1 using the broadspectrum blocker bumetanide [32,33]. To check for potential unspecific effects of bumetanide, we repeated all our measurements in cells transduced with a wellcharacterized RNA interference sequence to knock down the expression of NKCC1 [21,23,34].

To validate the use of the short hairpin RNA (shRNA) sequence designed and characterized by Ge et al. [21], we performed immunohistochemical staining for NKCC1 on RMS neuroblasts. We compared the staining in cells transduced with either a lentiviral vector encoding GFP and a non-encoding control sequence (hereafter called the control) or a vector encoding GFP and the shRNA for NKCC1 (hereafter called shNKCC1). Two sets of experiments were done. First, we compared the number of neuroblasts coexpressing GFP and NKCC1 in slices transduced with either the control or the shNKCC1 encoding sequences after 1 and $6 \mathrm{dpi}$ (Figure 2). Second, we compared the number of $\mathrm{GFP}^{+}$/ $\mathrm{NKCC}^{+}$cells in both the RMS and the GCL at $6 \mathrm{dpi}$ transduced with either one of the sequences (Additional file 4). In both sets of experiments, we found a significant difference between groups using the Kruskal-Wallis test: values for each experiment were $\mathrm{H}=33.82(P=0.1 \times$ $\left.10^{-4}\right)$ and $\mathrm{H}=38.13\left(P=0.1 \times 10^{-4}\right)$. Subsequent MannWhitney comparisons between the groups showed a significantly higher proportion of neuroblasts positive for NKCC1 in slices transduced with the control sequence compared to those transduced with shNKCC1 at $6 \mathrm{dpi}$ : values changed in the first experiment from $0.69 \pm 0.05$ ( $\mathrm{n}=85$ cells $)$ to $0.13 \pm 0.07(\mathrm{n}=41$ cells $), P=1 \times 10^{-}$ 3 and in the second experiment from $0.80 \pm 0.09$ ( $\mathrm{n}=$ 58 cells $)$ to $0.25 \pm 0.11(\mathrm{n}=63$ cells $), P=1 \times 10^{-4}$. 
A

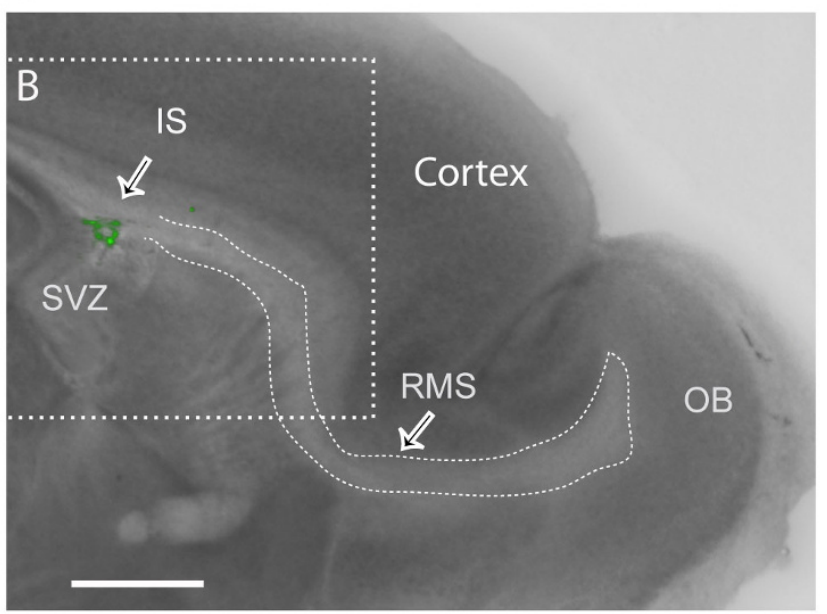

C

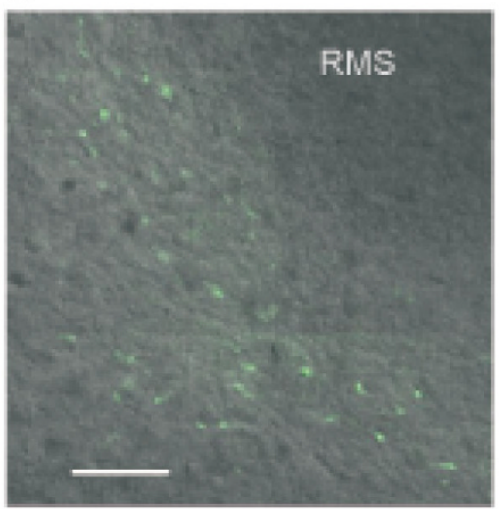

D

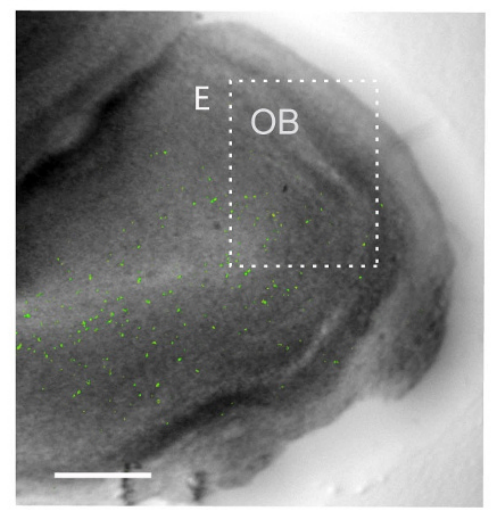

B

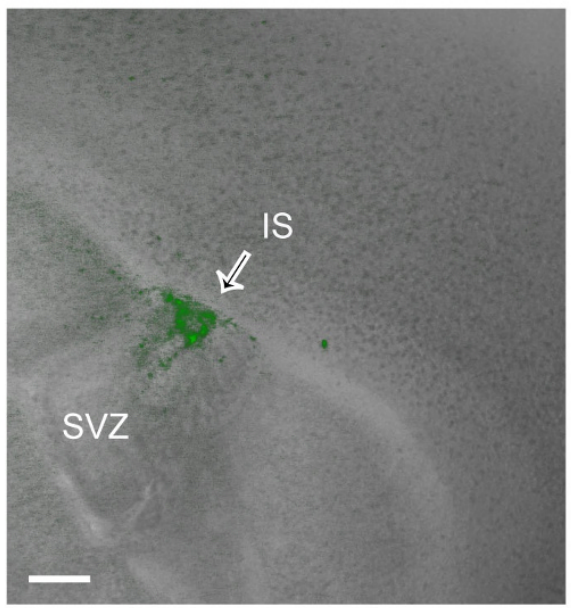

E

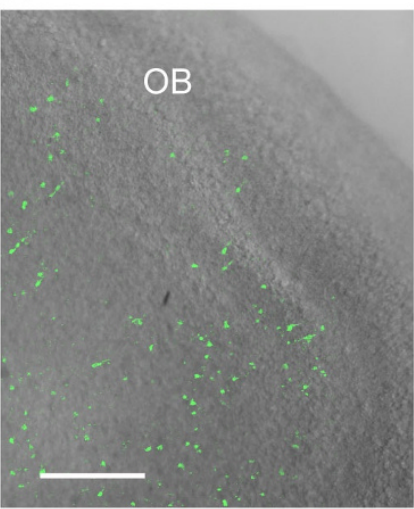

Figure 1 The injection of lentiviral vectors in the SVZ of organotypic slice cultures gives rise to $\mathrm{GFP}^{+}$migrating neuroblasts in the RMS and labeled neurons in all OB layers. (A) Photomicrograph of a cultured mouse forebrain sagittal section containing the SVZ-RMS pathway, showing the viral injection site (IS) in the SVZ at 2 days post-injection (dpi). Scale bar: $800 \mu \mathrm{m}$. Inset. Approximate location of the image shown in (B). (B) Detail of the IS displayed in (A) at higher magnification. Scale bar: $200 \mu \mathrm{m}$. (C) Photomicrograph showing GFP+ cells migrating in the RMS at 5 dpi. Scale bar: $100 \mu \mathrm{m}$. (D) Photomicrograph of the entire OB showing the arrival of GFP ${ }^{+}$cells at 5 dpi. Scale bar: $500 \mu \mathrm{m}$. The outline represents the approximate location of the magnification in (E). (E) Photomicrograph of the area outlined in (D), magnified to show GFP+ cells scattered throughout all OB layers. The same slice culture used in (D) is shown at 11 dpi. Scale bar: $200 \mu \mathrm{m}$.

In contrast, the proportion of $\mathrm{NKCC}^{+} \mathrm{GCs}$ was small in control slices $(0.22 \pm 0.05 ; \mathrm{n}=27$ cells $)$ and did not significantly change in shNKCC1 slices at $6 \mathrm{dpi}(0.05 \pm$ $0.03 ; \mathrm{n}=17$ cells; $P=0.09$ ). In slices injected with the shNKCC1-encoding vector, we observed a significant reduction in the proportion of $\mathrm{GFP}^{+} / \mathrm{NKCC}^{+}$neuroblasts when comparing results at 1 and $6 \mathrm{dpi}$ (from $0.81 \pm 0.03$ to $0.13 \pm 0.07 ; \mathrm{n}=22$ and 41 cells; $P=1$ $\left.\times 10^{-3}\right)$. Meanwhile, no difference was observed between 1 and $6 \mathrm{dpi}$ in slices injected with the control vector $(0.73 \pm 0.03$ and $0.69 \pm 0.05 ; \mathrm{n}=67$ and 85 cells; $P=0.25)$. The significance reported in this section takes into account the adjustment for $P$-values using the Bonferroni method.
Our immunohistochemical studies show that the shRNA interference strategy used in this study is efficient to reduce the expression of NKCC1 in neuroblasts, and coincides with its previously proven efficacy in the hippocampus [21,34] and the cortex [23]. Moreover, our results show that the expression of $\mathrm{NKCC} 1$ is reduced when the newborn cells leave the RMS to integrate the GCL.

NKCC1 activity is necessary to maintain normal migration speed in RMS neuroblasts

We explored whether the diminution in the activity of NKCC1 could impair the migration of neuroblasts in the RMS. For this, we compared the tangential migration of cells transduced with the non-target shRNA-GFP 


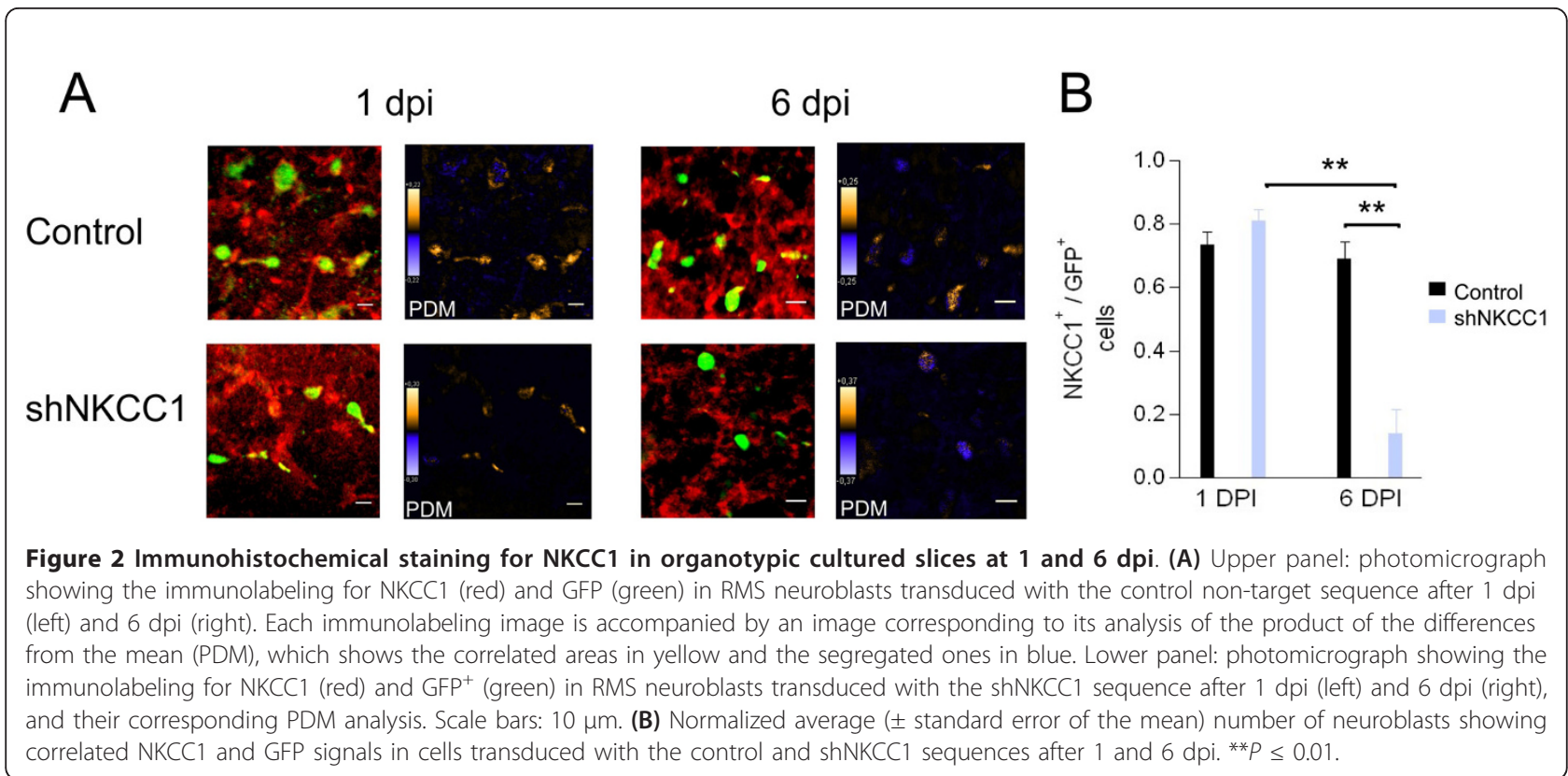

(control) against control cells in slices incubated in $10 \mu \mathrm{M}$ bumetanide 1 hour before and during the time lapse recording. A similar approach was employed with cells transduced with the shNKCC1-GFP virus. We calculated the average migration speed and the total displacement $(\Delta \mathrm{X})$ along the horizontal axis of the RMS in 202 cells (from 9 slices) for controls; 61 cells (4 slices) incubated in bumetanide, and 83 cells (from 8 slices) transduced with shNKCC1, in 7 independent experiments. Control neuroblasts migrated with an average speed of $42.2 \pm 2.0 \mu \mathrm{m} / \mathrm{h}$. The migration speed became significantly slower in cells incubated in bumetanide (32.4 \pm 4.7 $\mu \mathrm{m} / \mathrm{h} ; P=0.02)$ or transduced with shNKCC1 $(31.9 \pm 3.1$ $\mu \mathrm{m} / \mathrm{h}, P=0.007$ ) (Figure 3A; Additional files 5 and 6 ).

Figure 3B illustrates RMS neuroblasts migrating back and forth with respect to the OB. To investigate whether NKCC1 was required for determining the net tendency of the cells to migrate towards the $\mathrm{OB}$, we compared the total displacement of cells along the $\mathrm{x}$-axis, and used it as an index for directionality (Figure $3 \mathrm{C}$ ). The initial cell position was set to zero and the values of displacement were considered negative when cells moved towards the injection site (that is, the SVZ) and positive when cells headed towards the bulb. We found no significant differences in the values of $\Delta x$ between control cells and cells incubated in bumetanide or transduced with the $\operatorname{shNKCC1}(P=0.9$ and 0.6 , respectively).

NKCC1 modulates the migration speed in a $\mathrm{GABA}_{\mathrm{A}^{-}}$ independent manner

GABA acting on $\mathrm{GABA}_{\mathrm{A}}$ receptors reduces the migration of neuroblasts [12]. In order to test whether the effects observed by reducing the activity of NKCC1 were due to changes in the action of $\mathrm{GABA}_{\mathrm{A}}$ receptors, as a consequence of a potential drop in $\left[\mathrm{Cl}^{-}\right]_{\mathrm{i}}$, we analyzed the effects of blocking $\mathrm{GABA}_{\mathrm{A}}$ receptors with $10 \mu \mathrm{M}$ gabazine in slices transduced with the control sequence, in slices transduced with the control sequence and treated with bumetanide, and in slices transduced with the shNKCC1 sequence.

We analyzed 69 cells transduced with the shNKCC1 sequence (from 4 slices), 43 cells treated with bumetanide (from 3 slices) and 112 cells transduced with the control sequence (from 5 slices); all were recorded in the presence of gabazine during the experiments. Our results were compared using a two-way ANOVA, which showed significant differences between the group injected with the control sequence, the group injected with control sequence and treated with bumetanide and the shNKCC1 sequence group $\left(P=1 \times 10^{-6}\right)$, as well as a significant effect of gabazine $\left(P=1 \times 10^{-6}\right)$. The differences between individual groups were then evaluated using a Tukey posthoc test. The comparisons show an increase in the average migration speed due to the $\mathrm{GABA}_{\mathrm{A}}$ receptor blockade in the three groups (Figure 4A). The average speed of control cells treated with gabazine was significantly faster than in the non-treated control group $(53.9 \pm 1.5$ compared to $42.2 \pm 2 \mu \mathrm{m} / \mathrm{h}$; $P=1 \times 10^{-3}$; Figure $\left.4 \mathrm{~A}\right)$. Gabazine also significantly accelerated the speed of migration when comparing bumetanide groups (from $34.4 \pm 2.8$ to $45.5 \pm 2.5 \mu \mathrm{m} / \mathrm{h}$; $P=0.01$ ) and shNKCC1-treated cells (from $31.9 \pm 3.1$ to $42.5 \pm 1.6 \mu \mathrm{m} / \mathrm{h} ; P=0.01$ ). The cumulative distribution curve shifted to the right in all the groups treated 


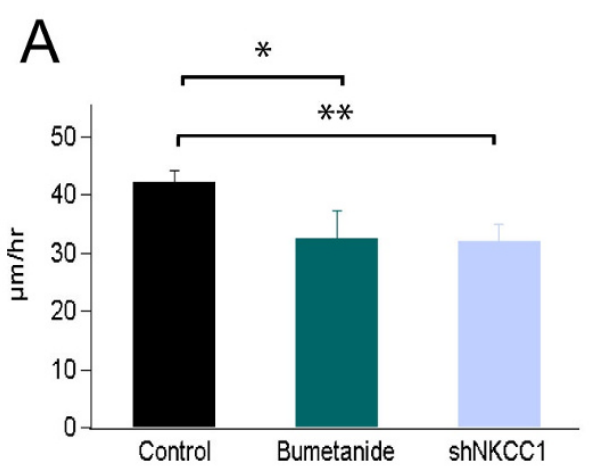

B
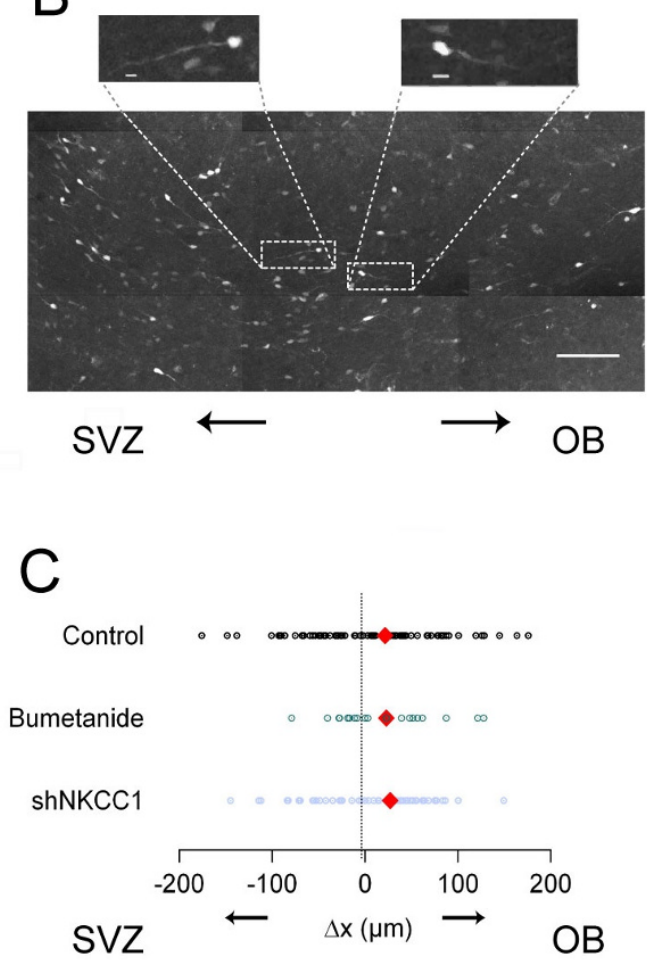

Figure 3 The activity of NKCC1 regulates the migration speed of RMS neuroblasts. (A) Plot showing the average migration speed of neuroblasts during a 3 hour recording session. Three groups are plotted: control (transduced with a control non-target shRNA sequence), bumetanide (transduced with a control nontarget shRNA sequence and incubated in $10 \mu \mathrm{M}$ bumetanide), and shNKCC1 (transduced with shNKCC1). (B) Photomicrograph of tangentially migrating GFP ${ }^{+}$neuroblasts in the RMS. The RMS was aligned horizontally so that changes along the x-axis represent displacement towards or away from the OB. Scale bar: $100 \mu \mathrm{m}$. Insets: detail of the directionality of the leading process in migrating neuroblasts. Scale bars: $10 \mu \mathrm{m}$. (C) Analysis of the migration directionality during the experimental session in the groups of cells described in (A). Displacement towards the SVZ is given a negative value whereas movements towards the $\mathrm{OB}$ are positive. Each point represents the total distance covered by one cell during the experimental session and the cells' initial position is at the origin. A red diamond represents the median value for each group. For this and the following figures ${ }^{*} P<0.05$ and ${ }^{*} P<0.01$.
A

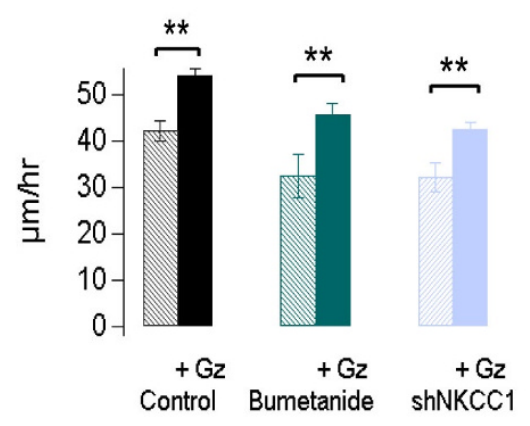

B

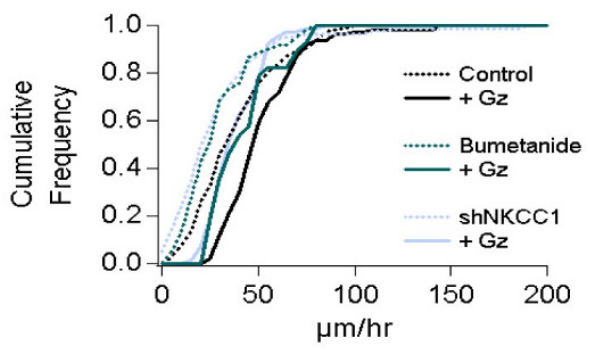

C

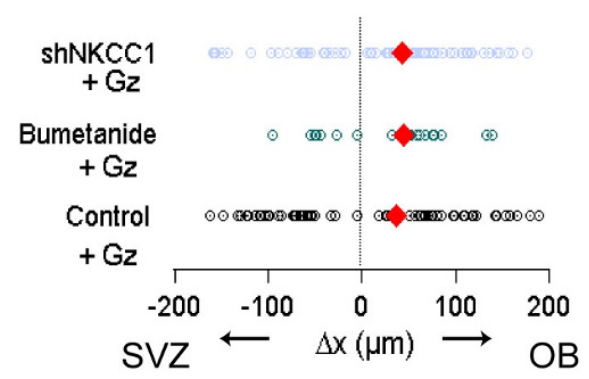

Figure 4 NKCC1 affects migration of neuroblasts in a $\mathrm{GABA}_{\mathrm{A}^{-}}$ independent manner. (A) Plot of the average migration speed of neuroblasts from the control, bumetanide and shNKCC1 groups (hatched bars) and these groups after incubation in $10 \mu \mathrm{M}$ gabazine (+Gz; solid bars). Error bars indicate standard error of the mean. (B) Normalized cumulative plot for the averaged migration speed in the groups displayed in (A). The shift to the leftward direction in the bumetanide and shNKCC1-transduced cells treated with gabazine compared to the gabazine treated control group indicates $G A B A_{A^{-}}$ receptor-independent effects (solid lines). (C) Analysis of the directionality of the migration during the experimental session in control, bumetanide-treated and shNKCC1-transduced cells incubated in gabazine. Analysis of directionality of migration as in Figure $3 C$.

with gabazine, compared with their respective controls (Figure 4B). The Kolmogorov-Smirnov test revealed no significant difference in the distribution of the average speed between control groups and bumetanide or shNKCC1 groups treated with gabazine $(P=0.99$ and $0.13)$. Overall, the analysis shows a very significant effect of NKCC1 pharmacological and genetic blockade as well as a significant effect of $\mathrm{GABA}_{\mathrm{A}}$-receptor blockers on the speed of migration of neuroblasts. Since the 
interaction between these two variables was not statistically significant $(P=0.78)$, we conclude that the role of NKCC1 on the maintenance of migration speed is independent of the modulation exerted by $\mathrm{GABA}_{\mathrm{A}}$ receptors.

To explore the effects of $\mathrm{GABA}_{\mathrm{A}}$ signaling on the directionality of the migration, we analyzed the displacement of the neuroblasts along the $\mathrm{x}$-axis, as explained in the previous section. We did not observe any effect on direction after the blockade of $\mathrm{GABA}_{\mathrm{A}}$ receptors in any of the groups treated with gabazine - that is, control, bumetanide and shNKCC1 groups - compared to their respective non-treated groups $(P=0.8,0.56$ and 0.7 , respectively; Figure $4 \mathrm{C}$ ). Altogether, our results show that neither NKCC1 nor the $\mathrm{GABA}_{\mathrm{A}}$-mediated activity are important in determining the directionality of RMS migrating neuroblasts.

Concerning the speed of migration, our experiments show that activation of $\mathrm{GABA}_{\mathrm{A}}$ receptors diminishes the migration speed in a way compatible with previous observations [12]. Moreover, the experiments performed in the presence of gabazine showed that the effects of NKCC1 on neuroblast migration do not depend on $\mathrm{GABA}_{\mathrm{A}}$ signaling.

\section{A tonic GABAergic current is active in both migrating neuroblasts and maturing GCs}

Our whole-cell recordings show that migrating neuroblasts do not receive spontaneous synaptic inputs, confirming previous studies [13]. The lack of synaptic inputs in neuroblasts holds even after treatment with alpha-latrotoxin to trigger massive neurotransmitter release (data not shown, $\mathrm{n}=3$ cells from 3 slices) $[35,36]$. In contrast, newly formed GCs displayed spontaneous synaptic activity, which started at $6 \mathrm{dpi}$ and significantly increased at $10 \mathrm{dpi}$.

Due to the lack of synaptic activity in neuroblasts, the action of GABA on the migration speed must depend on a tonic influence of this neurotransmitter. This mechanism has been suggested [12] but the tonic currents have never been recorded. Thus, we recorded the spontaneous activity of $\mathrm{GFP}^{+}$cells ( 5 to $11 \mathrm{dpi}$ ) held at $-60 \mathrm{mV}$ before and after applying the $\mathrm{GABA}_{\mathrm{A}}$ receptor blocker gabazine $(10 \mu \mathrm{M}) . \mathrm{GFP}^{+}$cells were either migrating neuroblasts located in the RMS (Figure 5A) or, for comparison, neurons located in the GCL (Figure 5B). In the GCL we paid particular attention to avoid recording from migrating $\mathrm{GFP}^{+}$cells, most likely representing newborn PGCs en route to the glomerular layer. Our results confirm the tonic action of $\mathrm{GABA}_{\mathrm{A}}$ receptors in neuroblasts and extend the observation to GCs. Moreover, they show that $10 \mu \mathrm{M}$ gabazine, the same concentration used in our migration studies, efficiently blocks the tonic $\mathrm{GABA}_{\mathrm{A}^{-}}$ mediated currents, which became evident from a diminution in holding current of $4.0 \pm 0.7 \mathrm{pA}$ in migrating

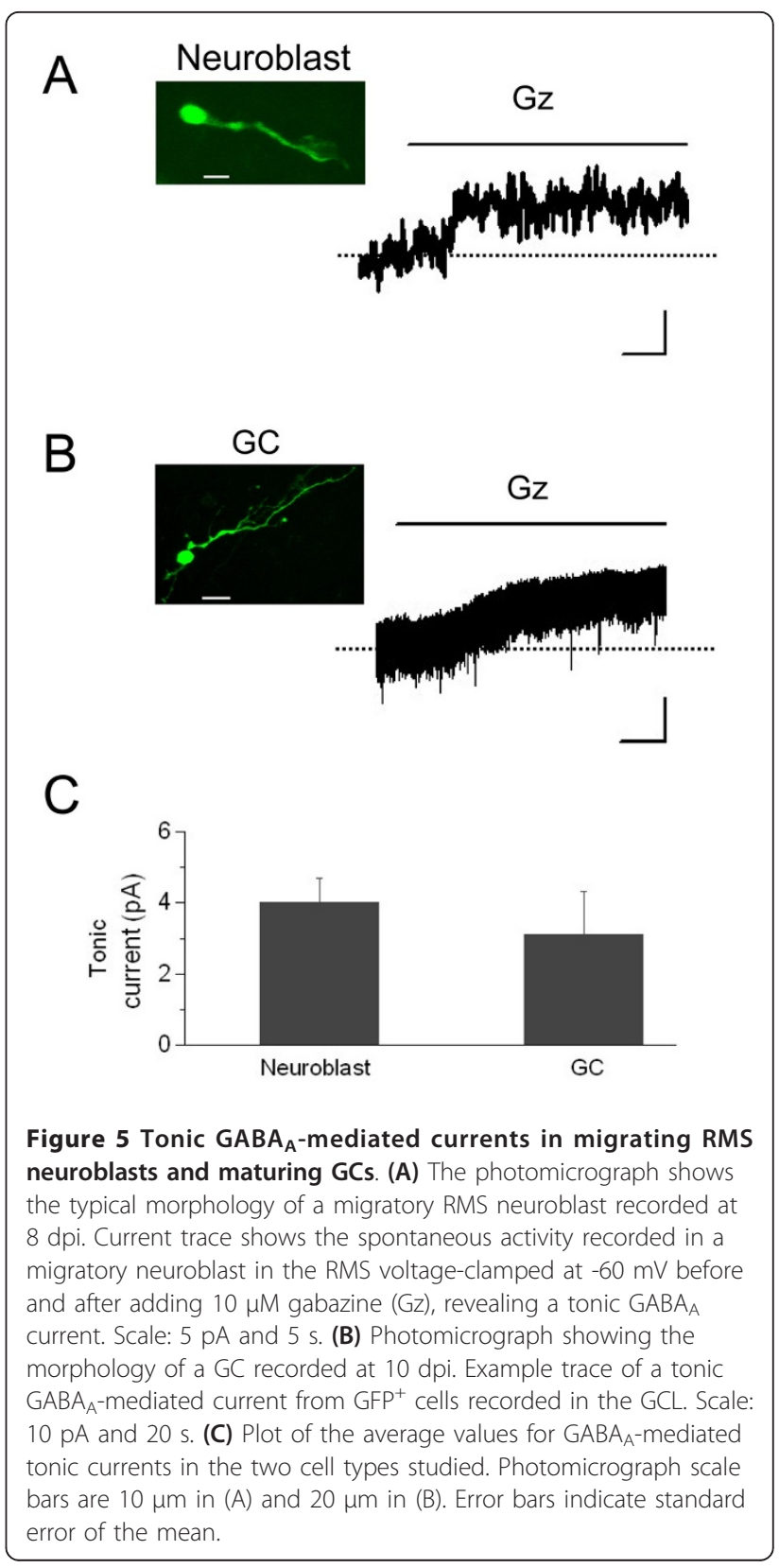

neuroblasts ( $\mathrm{n}=10$ cells from 9 slices; $P=9 \mathrm{e}-4$, paired $t$-test) and of $3.1 \pm 1.2 \mathrm{pA}$ in GCs ( $\mathrm{n}=6$ cells from 6 slices; $P=0.02$, paired $t$-test) (Figure $5 \mathrm{C}$ ) [37].

NKCC1 controls $\mathrm{E}_{\mathrm{GABA}}$ in RMS neuroblasts but not in GCs In order to understand the effects observed on neuroblast migration, we decided to determine whether and, if so, how the activity of NKCC1 affects the action of $\mathrm{GABA}_{\mathrm{A}}$ receptors and the overall excitability of the neuroblasts. For this we measured $\mathrm{E}_{\mathrm{GABA}}$ (the reversal potential for $\mathrm{GABA}_{\mathrm{A}}$ mediated responses) in RMS cells transduced with the control sequence and incubated in $10 \mu \mathrm{M}$ bumetanide or in cells transduced with the 
shNKCC1 sequence. As a reference, we repeated our measurements in newborn cells at a more mature stage, that is, in $\mathrm{GFP}^{+}$GCs.

Gramicidin-perforated patch-clamp recordings were carried out to determine $\left[\mathrm{Cl}^{-}\right]_{\mathrm{i}}$, and the strength of $\mathrm{GABA}_{\mathrm{A}}$ mediated responses. A voltage-ramp from -80 to $+20 \mathrm{mV}$ was applied in the presence and absence of a focal application of $10 \mu \mathrm{M}$ muscimol (pressure ejected near the cell soma). The resulting currents were subtracted to calculate $\mathrm{E}_{\mathrm{GABA}}$ (Figure 6Ai,Bi). Our results show that NKCC1 is an important modulator of GABA action in neuroblasts, since the diminution of its activity by either of the means tested produced a significant hyperpolarization of $\mathrm{E}_{\mathrm{GABA}}$. $\mathrm{E}_{\mathrm{GABA}}$ in migrating RMS neuroblasts shifted from $-29.8 \pm$ $1.7 \mathrm{mV}$ ( $\mathrm{n}=6$ cells from 6 slices) in control to $-49.7 \pm 2.8$ $\mathrm{mV}$ in bumetanide ( $\mathrm{n}=9$ from 6 slices; $P=0.01)$ and to $-56.7 \pm 2.3 \mathrm{mV}$ in shNKCC1-treated neuroblasts $(\mathrm{n}=8$ from 7 slices; $P=4 \times 10^{-4}$ ) (Figure 6Bii).

In contrast, new $\mathrm{GCs}$ had $\mathrm{E}_{\mathrm{GABA}}$ values significantly more hyperpolarized than neuroblasts in the control $\left(-57.5 \pm 4.1 \mathrm{mV} ; \mathrm{n}=13\right.$ from 13 slices; $P=6.9 \times 10^{-5}$; Figure 6Aii) and this value was not sensitive to either bumetanide $-58.6 \pm 3.6 \mathrm{mV}$ ( $\mathrm{n}=12$ from 10 slices; $P=$ $0.99)$ or shNKCC1 treatment $(-52.8 \pm 3.3 \mathrm{mV} ; \mathrm{n}=6$ from 5 slices; $P=0.94$ ) (Figure 6Bii).

We controlled for possible bias in our measurements due to the concentration of $\mathrm{Cl}^{-}$in the patching solution. The comparison of $\mathrm{E}_{\mathrm{GABA}}$ values between independent groups of cells using pipette solutions containing either a low or a high $\left[\mathrm{Cl}^{-}\right]$(solutions 1 and 2 in Materials and methods $)$ did not show any difference $(P=0.47)$ so the results were pooled. Furthermore, an additional control using immunohistochemical labeling for KCC2 showed that the hyperpolarization of $\mathrm{E}_{\mathrm{GABA}}$ in neuroblasts transduced with shNKCC1 is not due to a compensatory expression of $\mathrm{KCC} 2$, since no positive $\mathrm{KCC} 2$ labeling was observed in either $\mathrm{GFP}^{+}$neuroblasts or $\mathrm{GFP}^{+} \mathrm{GCs}$ (Additional file 7).

We used $E_{\mathrm{GABA}}$ values to estimate $\left[\mathrm{Cl}^{-}\right]_{\mathrm{i}}$ in both neuroblasts and GCs in the control and after treatments (Figure 6C). According to the effects on $\mathrm{E}_{\mathrm{GABA}}$, the calculated values of $\left[\mathrm{Cl}^{-}\right]$decreased from $43.5 \pm 3.1 \mathrm{mM}$ in control neuroblasts to $21.4 \pm 2.3 \mathrm{mM}\left(P=6.14 \times 10^{-5}\right)$ in bumetanide- and $15.9 \pm 1.3 \mathrm{mM}\left(P=1.09 \times 10^{-5}\right)$ in shNKCC1-treated cells. In newly formed GCs the values of $\left[\mathrm{Cl}^{-}\right]$in bumetanide- $(16.4 \pm 2.6 \mathrm{mM} ; P=0.99)$ and shNKCC1-treated cells $(17.2 \pm 2.8 \mathrm{mM} ; P=1)$ were not significantly different from those in the control (17.5 \pm $2.7 \mathrm{mM}$ ). The lack of effect of the treatments diminishing NKCC1 activity on GCs agrees with the low expression of NKCC1 observed in the immunohistochemical analysis (Additional file 4B,C).

The values of $\mathrm{E}_{\mathrm{GABA}}$ and $\left[\mathrm{Cl}^{-}\right]$were constant in each cell type for the duration of our study as no significant correlation between $\mathrm{E}_{\mathrm{GABA}}$ and dpi was observed in Spearman correlation tests $(r=-0.11$ for neuroblasts and $\mathrm{r}=-0.22$ for GCs; Additional file 8).

\section{NKCC1 controls the resting membrane potential in RMS neuroblasts}

To understand the net effect of the activation of conductance on a cell's membrane potential, it is useful to determine the value of the potential at rest. The resting membrane potential (RMP) was measured in the cellattached mode as the equivalent of the reversal potential of $\mathrm{K}^{+}$conductances using isotonic intra- and extracellular concentrations of this ion [38]. We did verify that, in our system, this method was sensitive to predictable changes in RMP by measuring the reversal of $\mathrm{K}^{+}$currents before and after raising the extracellular $\left[\mathrm{K}^{+}\right]$to $10 \mathrm{mM}$. This manipulation produced an average $3.4 \pm$ $1.6 \mathrm{mV}$ depolarization in the four cells tested.

We then measured the RMP in migrating neuroblasts and GCs in control slices. Remarkably, we did not find significant differences in RMP values between these cell groups: $-71.5 \pm 3.6 \mathrm{mV}$ ( $\mathrm{n}=6$ from 5 slices $)$ and -71.0 $\pm 4.4 \mathrm{mV}$ ( $\mathrm{n}=6$ from 6 slices; $P=0.93, t$-test), respectively. Nonetheless, the comparison of RMP in neuroblasts treated with bumetanide or shNKCC1 showed a depolarization due to the diminution of NKCC1 activity. The measured values were $-59.8 \pm 3.2 \mathrm{mV}(\mathrm{n}=6$ from 5 slices; $P=0.07$ ) for bumetanide and $-58.7 \pm 2.9 \mathrm{mV}$ ( $\mathrm{n}=9$ from 5 slices; $P=0.02$ ) in cells expressing shNKCC1 (Additional file 9). In contrast, in GCs the diminution of NKCC1 activity did not produce significant changes in RMP compared to control; values of $-67.0 \pm 1.0 \mathrm{mV}(\mathrm{n}=2$ from 2 slices; $P=0.90)$ in bumetanide- and $-69.4 \pm 6.1 \mathrm{mV}(\mathrm{n}=5$ from 5 slices; $P=$ 0.97) in shNKCC1-treated cells.

We used the $\mathrm{E}_{\mathrm{GABA}}$ values from muscimol-mediated currents and the RMP values to calculate the driving force for GABA-mediated responses. In neuroblasts, both the hyperpolarization of $\mathrm{E}_{\mathrm{GABA}}$ as well as the depolarization of about $11 \mathrm{mV}$ in their RMP, observed in bumetanide and shNKCC1 groups, resulted in an important decrease in the driving force for GABA responses, with the strongest effects on the shNKCC1treated group. The calculated driving force value in control neuroblasts $(41.7 \pm 2.8 \mathrm{mV})$ was significantly diminished to $10.2 \pm 2.9 \mathrm{mV}\left(P=2.84 \times 10^{-5}\right)$ in bumetanide- and to $2.0 \pm 2.6 \mathrm{mV}\left(P=1.03 \times 10^{-5}\right)$ in shNKCC1-treated cells. Moreover, as expected from the lack of effect of the diminution of NKCC1 activity on both $\mathrm{E}_{\mathrm{GABA}}$ and RMP in GCs, we did not observe any effect on the driving force between control GCs (13.5 \pm $4.2 \mathrm{mV})$ and the bumetanide- $(10.81 \pm 3.6 \mathrm{mV} ; P=$ $0.98)$ or shNKCC1-treated groups $(16.6 \pm 4.8 \mathrm{mV} ; P=$ 0.99) (Figure 6Aiii). 


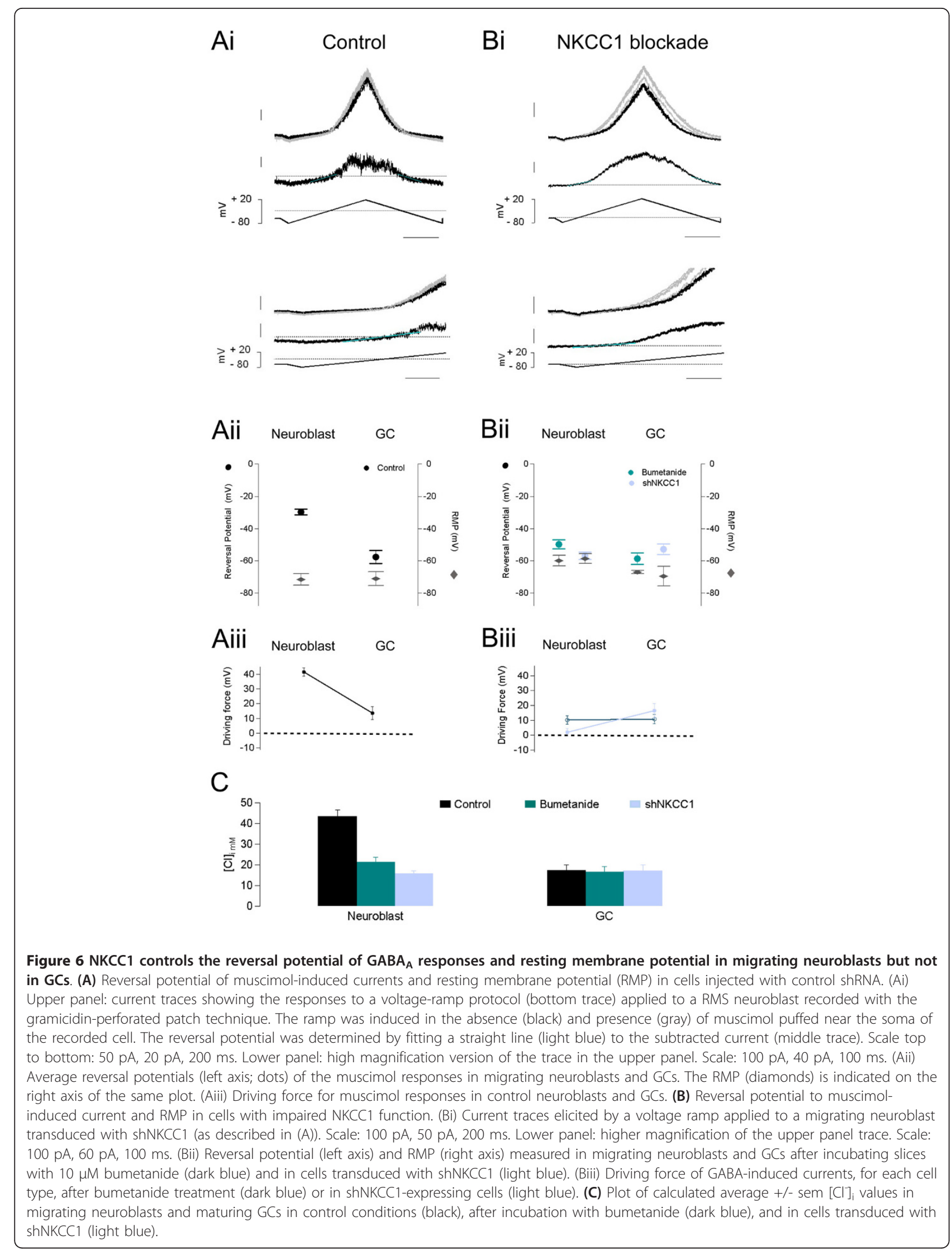


A comparison between cell types - neuroblasts versus GCs - in the control condition shows a significant decrease in the driving force for $\mathrm{GABA}_{\mathrm{A}}$-mediated responses in newborn interneurons when reaching the bulb $\left(P=5.28 \times 10^{-5}\right.$; Figure 6Aiii,Biii). Nonetheless, GABA maintained a depolarizing action on both cell types. Our results indicate that NKCC1 expression is diminished in GCs from the time of their arrival at the OB. Therefore, in sharp contrast to neuroblasts, neither the action of GABA nor the values of RMP depend on NKCC1 activity in developing GCs.

Finally, we verified whether gabazine was able to change the RMP in neuroblasts, as would be expected from the measured driving forces for muscimol responses. In control cells, gabazine induced a $2.3 \pm 0.8$ $\mathrm{mV}$ ( $\mathrm{n}=3$ cells) hyperpolarization of the RMP while only a $0.45 \pm 0.04 \mathrm{mV}$ hyperpolarizing shift was observed in shNKCC1 neuroblasts $(n=2)$. The lesser effect of gabazine on RMP in shNKCC1 cells supports the diminished driving force for muscimol observed in these cells. Moreover, the lesser effect on RMP observed in shNKCC1 cells might be related to the decreased effect of gabazine on the acceleration of neuroblast migration in the bumetanide and shNKCC1 cells (Figure 4).

\section{Discussion}

In the present study we characterize the role of NKCC1 on the regulation of the migration and excitability of migratory neuroblasts and developing $\mathrm{OB}$ interneurons in early postnatal tissue. We found that NKCC1 activity is important for the neuroblasts to maintain a normal migratory speed since two independent manipulations employed to impair NKCC1 function, pharmacological blockade with bumetanide and transduction with shNKCC1, produced a diminution of the migration speed (Figure 3A). Meanwhile, the manipulation of NKCC1 did not affect the directionality of migration (Figure 3C), suggesting that these two aspects are regulated by different mechanisms.

We performed electrophysiological measurements to determine the effects of NKCC1 on the excitability of migratory neuroblasts. Our results show that, similar to other developing neurons [19-21], the activity of NKCC1 maintains a high concentration of $\left[\mathrm{Cl}^{-}\right]_{\mathrm{i}}$ in $\mathrm{RMS}$ neuroblasts (Figure 6Bii). In addition, we demonstrate that the activity of this cotransporter is necessary to keep a hyperpolarized RMP in neuroblasts (Figure 6Bii), and thus to control the resting excitability in these cells in a manner independent of the regulation of $\mathrm{Cl}^{-}$fluxes initiated by neurotransmission. This result supports previous studies showing modifications of RMP and neuronal excitability after manipulation of $\mathrm{Cl}^{-}$cotransporters in different types of neurons [20,39-41]. It is likely that changes in the ionic concentration of $\mathrm{Na}^{+}$contributed by the activity of $\mathrm{Cl}^{-}$cotransporters alter the homeostasis and resting potential of the cells. Along these lines, manipulations depleting the internal concentration of this ion have been shown to depolarize the RMP of neonatal neurons [39]. Possible explanations relating the alterations in $\mathrm{Na}^{+}$fluxes and modulations of RMP could involve diminished electrogenic activity of ionic carriers such as $\mathrm{Na}^{+} / \mathrm{K}^{+}$ATPase, thus producing a depolarization of the RMP [42], or changes in the magnitude of $\mathrm{K}$ + conductances, very prominent in the RMS neuroblasts [13]. The exact mechanisms explaining the significant depolarization of RMP observed in the RMS neuroblasts after the blockade of NKCC1 is beyond the scope of the present study. Nevertheless, the alteration of RMP after the blockade of $\mathrm{Cl}^{-}$cotransporters observed for the first time in migratory neuroblasts in the present study and in other cell types in previous reports (see above) suggests a relevant role for NKCC1 in the control of resting excitability in developing neuronal cells.

Our results show that the blockade of $\mathrm{GABA}_{\mathrm{A}}$ receptors accelerates the migration speed of the neuroblasts in the RMS. These observations are in agreement with previous reports showing that tonically released GABA acts on $\mathrm{GABA}_{\mathrm{A}}$ receptors to diminish the velocity of migration in RMS neuroblasts $[12,43,44]$, as well as in the cortex [45]. In our study, the speed of migration was accelerated by $\mathrm{GABA}_{\mathrm{A}}$ pharmacological blockade in both neuroblasts transduced with the control sequence and those treated with bumetanide or transduced with shNKCC1. This is in agreement with the depolarizing driving force for GABA measured in all groups of cells (Figure 6Aiii,Biii), as well as with the hyperpolarization of RMP values observed after treating the cells with gabazine. The statistical analysis of the effects of blockers of $\mathrm{GABA}_{\mathrm{A}}$ receptors and $\mathrm{NKCC1}$ shows a lack of interaction between these two mechanisms. Thus, our results strongly support the notion that the motogenic action of NKCC1 does not depend on the activity of $\mathrm{GABA}_{\mathrm{A}}$ receptors. It is very likely that the effects of NKCC1 blockade on neuroblast migration are accounted for by the sustained depolarization of the RMP observed in cells with impaired NKCC1 function. In support of this hypothesis, a similar study by Bolteus and Bordey [12] shows that depolarization induced by $\mathrm{KCl}$ treatment diminishes the speed of RMS neuroblast migration. In that study, the diminution of speed induced by depolarization was only partially reverted, but not abolished, by the pharmacological blockade of $\mathrm{GABA}_{\mathrm{A}}$ receptors with $100 \mu \mathrm{M}$ bicuculline. Thus, our results, together with previous findings, show that the migration of neuroblasts is very sensitive to manipulations affecting the resting membrane potential, therefore suggesting that the relationship between the membrane potential and the speed of migration might be more important than previously thought. 
The precise way in which external and internal processes regulate neuroblast migration in the RMS remains unclear. Modifying bulbar neuronal activity has little effect on tangential migration. For instance, anosmia [46], naris occlusion [47], or surgical disruption of the RMS [48] failed to alter neuroblast migration. In contrast, migration in the RMS is highly sensitive to brain hyperexcitability, associated with status epilepticus [49], or to brain injury, which accelerates the speed of migration $[49,50]$. Further studies are needed to understand how these external signals can change neuroblast excitability and adjust their rate of integration into the OB circuits or injured brain areas. Considering the important role of NKCC1 in the integration of external signaling and resting excitability, further investigations should determine whether pathological brain activity can impact the function of this $\mathrm{Cl}^{-}$cotransporter, particularly since previous studies have shown that NKCC1 function is sensitive to activity-dependent modulation $[51,52]$. In this regard, a recent study showed that the pharmacological blockade of NKCC1 diminishes the proliferation of glial precursors induced by ischemia in the cortex [53].

\section{NKCC1 is inactivated during the transition from migrating RMS neuroblasts to GCs}

In the present study we used organotypic slice cultures to compare the role of NKCC1 on the excitability of neuroblasts and in maturing newborn neurons. The use of this model seems particularly appropriate for the present study since both the neuroblast migration and GC integration occur in the organotypic control, in a similar way to those reported from acute models [12,31]. First, the speed of migration in our system is remarkably similar to previous values measured in acute slices [12]. Moreover, the labeled precursors evolve in the organotypic culture, first as a contingent of neuroblasts migrating in the RMS to increasingly populate the OB. Once in the GCL, the cells change their morphology and show functional maturation (Figure 1; Additional file 3), including the development of synaptic activity. A similar system has been previously used to study the control of differentiation in dopaminergic cells [54].

Our results show that the early maturation of $\mathrm{OB}$ interneurons, at least when considering GCs, is paralleled by changes in both GABAergic signaling and NKCC1 function. After reaching the bulb, the neural precursors acquire a mature morphology and establish synaptic interactions with pre-existing neurons, some of which are GABAergic [55]. Our results show that GABA action evolves from a non-synaptic, temporally and spatially diffuse tonic influence in the RMS to include synaptic contacts on GCs during the first weeks of development. The tonic influence of GABA was preserved in GCs during the entire duration of our study, regardless of the development of synaptic contacts. These results are in agreement with a previous report showing that, in early postnatal tissue, GABA produced a depolarizing influence, capable of shunting the firing activity on GCs [56]. Correspondingly, we detected a small tonic current and a slightly positive driving force for $\mathrm{Cl}^{-}$in GCs (Figures 5 and 6A iii). Slightly positive driving forces for GABA are frequently observed in immature interneurons [57-59] and are believed to favor neuronal development [14].

The manipulations affecting the activity of NKCC1 showed that the strong depolarizing action of GABA in RMS neuroblasts largely depends on this $\mathrm{Cl}^{-}$transport system. Meanwhile, in GCs, GABA exerted a much weaker depolarizing driving force that was not affected by the manipulations blocking the activity of NKCC1. These results are confirmed by the immunohistochemical data showing a much higher proportion of neuroblasts expressing NKCC1 compared to GCs in slices injected with the control sequence, and a significant drop of $\mathrm{NKCC}^{+}$neuroblasts but not GCs in cells transduced with shNKCC1 (Additional file 4). In accordance with the functional and anatomical evidence of low expression of NKCC1 on GCs, we failed to find any effect of the manipulation of this $\mathrm{Cl}^{-}$transporter on the development of GC dendrite projections (data not shown). Thus, it seems unlikely that GC synaptic connectivity in the $\mathrm{OB}$ is shaped by $\mathrm{NKCC} 1$, in contrast to the dentate gyrus [21].

Wang and colleagues [56] showed that, after the second postnatal week, GABA hyperpolarizes the GC, held at $-60 \mathrm{mV}$, at the time that KCC2 mRNA appears. We observed a strong hyperpolarization of $\mathrm{E}_{\mathrm{GABA}}$ when $\mathrm{GFP}^{+}$cells reached the GCL. However, GABA action did not become hyperpolarizing during our study, possibly owing to delays in this process due to in vitro conditions, or because our recorded cells were young and did not yet express KCC2 (Additional file 7B). Several reports have shown that $\mathrm{KCC} 2$ mRNA expression is abundant in mature neurons, whilst negligible expression was detected in neuronal progenitors $[17,60]$. It is conceivable that, at later stages of maturation, $\mathrm{KCC} 2$ is involved in the synaptic connectivity of GCs, as it is in other systems [40,61]. Nonetheless, our results indicate that the first significant decrease in $\left[\mathrm{Cl}^{-}\right]_{\mathrm{i}}$ in $\mathrm{GCs}$, and therefore the simultaneous hyperpolarization of $\mathrm{E}_{\mathrm{GABA}}$, results from a functional down-regulation of NKCC1.

Altogether our data suggest that variations in NKCC1 activity can efficiently control various steps of OB postnatal neurogenesis. Accordingly, we show that an important change in the functional expression of this cotransporter accompanies the developmental transition from neuroblasts to developing GCs. NKCC1 is highly 
active in the RMS precursor cells and its functional expression drops drastically in the newborn GCs, greatly affecting the action of GABAergic signaling on this early period of functional integration. Concerning the neuroblasts in the RMS, our results show, for the first time, an important role of NKCC1 in the control of neuroblast excitability. Our electrical determinations indicate that NKCC1 controls at least two different aspects of neuroblast activity. The first concerns the control of $\left[\mathrm{Cl}^{-}\right.$ $\mathrm{l}_{\mathrm{i}}$ and therefore the integration of the most prominent neurotransmitter signaling system in the RMS, $\mathrm{GABA}_{\mathrm{A}^{-}}$ receptor-mediated activity $[12,13,31,43,62,63]$. The second aspect concerns the regulation of intrinsic excitability and depends on the control of the RMP. Thus, our study suggests that NKCC1 integrates relevant external signaling and the intrinsic neuronal excitability to finely tune the migration speed of RMS neuronal precursors en route to the OB.

\section{Materials and methods Culture preparation}

Postnatal day 7 C57BL/6J mouse pups (Janvier, Le Genest Saint Isle, France)) were decapitated and the brains removed and placed into ice-cold artificial cerebrospinal fluid (ACSF) containing (in $\mathrm{mM}$ ) $124 \mathrm{NaCl}, 3 \mathrm{KCl}, 1.3$ $\mathrm{MgSO}_{4}, 26 \mathrm{NaHCO}_{3}, 1.25 \mathrm{NaH}_{2} \mathrm{PO}_{4}, 10$ glucose and 2 $\mathrm{CaCl}_{2}$, saturated with $95 \% \mathrm{O}_{2} / 5 \% \mathrm{CO}_{2}$. Sagittal forebrain slices, $300 \mu \mathrm{m}$ thick, containing the migratory pathway from the SVZ-RMS and OB were prepared with a vibratome (Leica VT1200). All experimental procedures were performed in accordance with the Charter of Fundamental Rights of the European Union (2000/C 364/01), the European Communities Council Directive of 24 November 1986 (86/609/EEC), and European Union guidelines. They were reviewed and approved by our Institutional Animal Welfare Committee.

Each brain slice was transferred to a Millicell-CM Culture Plate Insert (Millipore PICM ORG 50; Billerica, MA, USA ), the excess ACSF was removed and the insert was placed in a $35-\mathrm{mm}$ Petri dish containing $1 \mathrm{ml}$ of medium, as described by Stoppini and colleagues [64]. Culture medium consisted of 46\% MEM (31095029, Invitrogen, Paisley, UK), 25\% HBSS (24020-091, Invitrogen), 25\% horse serum, $20 \mathrm{nM}$ HEPES, $6 \mathrm{mg} / \mathrm{ml}$ D-glucose and gentamycin (Invitrogen, Paisley, UK). The slices were incubated at $37^{\circ} \mathrm{C}$ in a humid atmosphere of $5 \% \mathrm{CO}_{2}$. The medium was changed three times per week.

\section{Lentiviral vectors}

We used lentiviral vectors created using the PTRIPDU3 method to express GFP in neural precursors and neuroblasts [65]. The first vector was constructed such that GFP expression was under the control of the PGK promoter. For the second vector, a previously published shRNA sequence for NKCC1, shNKCC1-1 (5'ACACACTTGTCCTGGGATT3'), was introduced under the control of the U6 promoter [21]. This vector was similar to the first, also containing a sequence to induce GFP expression, but under the control of the CMV promoter. As a control, we constructed a third vector in which the shRNA sequence was replaced with a non-target scrambled sequence (5'GCCAGATTTCTCAGGTGATAA3'). Twenty-four hours after culturing the slices, $270 \mathrm{pg}$ of p24 from one of the constructions was injected in the SVZ, in a volume of $18 \mathrm{nl}$.

\section{Electrophysiology}

$\mathrm{GFP}^{+}$RMS neuroblasts and olfactory bulb GCs, at 3 to $11 \mathrm{dpi}$, were recorded using the patch-clamp technique in different configurations as detailed below. For data acquisition and electrical control an EPC-10 amplifier (Heka Elektronik, Lambrecht/Pfalz, Germany ) was used. Before the recordings, a piece of Millicell membrane containing the slice was cut out and transferred to a chamber. During the recording session the slices were continuously perfused at a rate of $1.5 \mathrm{ml} /$ minute with extracellular solution containing (in $\mathrm{mM}$ ) $124 \mathrm{NaCl}, 3$ $\mathrm{KCl}$, 2.4 $\mathrm{CaCl}_{2}, 1 \mathrm{MgCl}_{2}, 25 \mathrm{NaHCO}_{3}, 1.25 \mathrm{NaH}_{2} \mathrm{PO}_{4}$, and 10 glucose. The extracellular solution was heated to $35^{\circ} \mathrm{C}$ at the entrance of the chamber (inline heater TC324B, Warner Instruments, Inc; Hamden, CT, USA). Glass pipettes with a resistance of 6 to $7 \mathrm{M} \Omega$ were used for the recordings.

The reversal potential of $\mathrm{GABA}_{\mathrm{A}}$-receptor-mediated currents was determined using the perforated patchclamp configuration with gramicidin - a cation-specific channel - in order to obtain voltage control of the cell while leaving $\left[\mathrm{Cl}^{-}\right]_{\mathrm{i}}$ intact [66]. For perforated-patch recordings one of the following patching solutions was used in each experiment: (1) $150 \mathrm{mM} \mathrm{KCl}, 10 \mathrm{mM}$ Hepes; or (2) $150 \mathrm{mM}$ KGluconate, $10 \mathrm{mM}$ Hepes, both at $\mathrm{pH}$ 7.5. A stock of $1 \mathrm{mg} / \mathrm{ml}$ of gramicidin was freshly prepared on the day of the experiment and a final concentration of $2 \mu \mathrm{g} / \mathrm{ml}$ was added to the patching solution. The pipette tip was dipped in gramicidin-free patching solution before backfilling it with the gramicidin-containing solution. A giga-seal was established with the cell membrane and the recording session began when a stable access resistance between 50 and $70 \mathrm{M} \Omega$ was obtained.

To determine the reversal potential of the currents elicited by the $\mathrm{GABA}_{\mathrm{A}}$ receptor agonist muscimol, a $1 \mathrm{~s}$ voltage-ramp from -80 to $+20 \mathrm{mV}$ and back to $-80 \mathrm{mV}$ was applied to cells recorded in the perforated configuration. Muscimol $(10 \mu \mathrm{M})$ was pressure ejected (10 to $20 \mathrm{psi}$ ) near the cell membrane during the ramp. At least three ramps were applied and averaged before and during 
muscimol application. The averaged currents were subtracted and the resulting trace was used to measure the reversal potential of the muscimol-triggered current. Reversal potentials were determined by linear fitting of the current trace using Igor (Wavemetrics, Inc; Lake Oswego, OR, USA), whereas $\left[\mathrm{Cl}^{-}\right]_{\mathrm{i}}$ was estimated from the Nernst equation. Repeated agonist application can influence the apparent $\mathrm{Cl}^{-}$reversal potential $\left(\mathrm{E}_{\mathrm{GABA}}\right)$, particularly in immature neurons in which $\mathrm{Cl}^{-}$regulation mechanisms are less effective [67]. Therefore, we ensured that the interval between agonist applications was sufficiently long (20 s) to avoid shifts in $\mathrm{E}_{\mathrm{GABA}}$.

To determine the cells' RMP we used the method described by Verheugen et al. [38]. Briefly, we kept the cells in the cell-attached mode at $-60 \mathrm{mV}$ and applied a voltage-ramp from -100 to $+200 \mathrm{mV}$ to activate a voltage-dependent $\mathrm{K}^{+}$conductance. Patching solutions 1 or 2 , described above, were used in the absence of gramicidin for these determinations. Both solutions have a concentration of $150 \mathrm{mM} \mathrm{K}^{+}$; therefore, the reversal potential of the $\mathrm{K}^{+}$conductance was assumed to be equal to the RMP. The difference between average RMP values and the reversal potential of the muscimolinduced current values was used to determine the driving force for GABA in each condition and cell type.

Tonic currents were recorded in the whole cell mode at $-60 \mathrm{mV}$ holding potential. For these recordings solution 1 was supplemented with $2 \mathrm{mM}$ ATPMg, $0.2 \mathrm{mM}$ GTPNa and $0.2 \mathrm{mM}$ EGTA. We recorded the spontaneous activity of the cells held at $-60 \mathrm{mV}$ for at least 2 minutes in normal ACSF before applying $10 \mu \mathrm{M}$ gabazine to the bath, and then recorded spontaneous activity for 5 minutes after the application of the drug. To measure the tonic $\mathrm{GABA}_{\mathrm{A}}$ current, we assessed the average holding current necessary to maintain the voltage at $-60 \mathrm{mV}$, during $10 \mathrm{~s}$ in control ACSF, starting $40 \mathrm{~s}$ before application of gabazine, and $30 \mathrm{~s}$ after its application in the bath. Bicuculline blocks SK-type $\mathrm{K}^{+}$channels [68] and may affect the measurement of tonic current. Thus, gabazine is the drug of choice for studying tonic GABA conductance. For one group of cells, $\mathrm{GABA}_{\mathrm{A}}$-dependent tonic currents were determined in the cells recorded first in the perforated-patch configuration and subsequently transformed into whole-cell mode by gentle suction within the recording pipette $(n=6$ neuroblasts and $3 \mathrm{GCs})$. A second group was recorded in whole cell mode in the absence of gramicidin on the intracellular pipette ( $n=4$ neuroblasts and 3 GCs). No significant differences were observed between the values obtained with either method, neither for the RMS neuroblasts $(P=0.57)$ nor for the GCs $(P=0.51)$; thus, the results were pooled.

Only the cells maintaining a stable access resistance (less than 20\% variation during the experiment) were analyzed. The series resistance values were between
10 and $25 \mathrm{M} \Omega$ and no compensation was applied. The spontaneous currents were filtered at $2.9 \mathrm{KHz}$ with a low-pass Bessel filter and were sampled at $8.33 \mathrm{KHz}$. To analyze the passive properties of cells, the currents generated by a $20 \mathrm{~ms}, 20 \mathrm{mV}$ hyperpolarizing pulse were filtered at $5 \mathrm{kHz}$ and sampled at $10 \mathrm{kHz}$. All values were corrected for the measured liquid junction potential ( -2 and $-8 \mathrm{mV}$ for solutions 1 and 2, respectively).

\section{Drugs}

All drugs were purchased from Sigma-Aldrich and used at the following concentrations: $10 \mu \mathrm{M}$ bumetanide was used to block NKCC1 activity. In all the experiments using bumetanide the slices were pre-incubated for $1 \mathrm{~h}$ in $10 \mu \mathrm{M}$ bumetanide and the same concentration was present during our electrophysiological and imaging recordings (Sigma-Aldrich, Saint-Quentin Fallavier, France). $10 \mu \mathrm{M}$ gabazine and $10 \mu \mathrm{M}$ muscimol were used as antagonist and agonist of $\mathrm{GABA}_{\mathrm{A}}$ receptors, respectively, and $10 \mathrm{nM}$ alpha-latrotoxin was used to trigger neurotransmitter release.

\section{Immunohistochemistry}

Organotypic brain slices were fixed in $4 \%$ paraformaldehyde before being cryoprotected in $12.5 \%$ sucrose, $5 \%$ glycerol for $2 \mathrm{~h}$ at $4^{\circ} \mathrm{C}$ and incubated overnight in $25 \%$ sucrose, $10 \%$ glycerol. Slices were rapidly frozen and thawed three times over liquid $\mathrm{N}_{2}$ vapor, washed in PBS before a second fixation in paraformaldehyde for 15 minutes, and incubated for $2 \mathrm{~h}$ in $10 \%$, NGS $0.1 \%$ Triton blocking solution at room temperature. For immunolabeling of chloride cotransporters, slices previously injected with one of the lentiviral vectors were then incubated at 1 or $6 \mathrm{dpi}$ in the primary antibody for NKCC1 (1:200; T4, Developmental Studies Hybridoma Bank) or at $6 \mathrm{dpi}$ in the antibody for KCC2 (1:200; 07 432, Upstate, Billerica, MA, USA) mixed with the antiGFP (1:1,000; 06-896, Upstate). A different set of organotypic slices at 6 div were incubated in the following primary antibodies: neuronal nuclei marker NeuN (1:200; MAB377, Chemicon, Billerica, MA, USA; $n=3$ ), DCX (1:1,000; Ab18723, Abcam, Cambridge, UK; $\mathrm{n}=3$ ), GABA (1:1,000; A2052, Sigma; $n=3)$ or TH (1:4,000; 22941, ImmunoStar, Hudson, Wisconsin, USA; $\mathrm{n}=3$ ). All primary antibodies were diluted in blocking solution and incubated for $48 \mathrm{~h}$ at $4^{\circ} \mathrm{C}$, followed by washes in PBS. Then, slices were incubated for $2 \mathrm{~h}$ in an alexaconjugated secondary antibody (Alexa Fluor 568 (1:750) for the chloride transporters and Alexa Fluor 488 (1:800) for the rest of the proteins; both from Molecular Probes, Paisley, UK) at room temperature and washed in PBS. NeuN, DCX, GABA and TH stained cultures were then incubated in DAPI for 15 minutes at room temperature and washed in PBS. All the slices were then 
mounted in ProLong Gold antifade (P36930, Molecular Probes). For analysis, images of 0.5 to $1 \mu \mathrm{m}$ thick were acquired either in an upright microscope (Zeiss), equipped with a confocal spinning disk unit (Andor, Belfast, UK) or in an inverted microscope (Axioscope FS, Zeiss), equipped with a structured illumination device (Apotome, Zeiss).

To determine the number of $\mathrm{GFP}^{+}$cells in the field that were also positive for NKCC1, we used the Intensity Correlation Analysis package of ImageJ [69]. The region analyzed was first defined by the limits of the GFP signal of a cell in the z-axis. Signal was considered a cell when the morphology corresponded to a round or elliptical cell body of 6 to $12 \mu \mathrm{m}$ with at least one projection. We considered as double labeled those cells showing a positive intensity correlation quotient for both GFP and alexa 568 signals. The number of labeled cells per field $(313 \times 313 \mu \mathrm{m})$ was determined in three independent images for each region of interest (RMS and GCL), and the results were normalized to the total number of $\mathrm{GFP}^{+}$cells analyzed in each image and then averaged (Figure 2; Additional file 4).

\section{Time-lapse videomicroscopy}

The Petri dish containing the cultured slice was transferred to a closed chamber with the temperature control adjusted to maintain the medium at $36^{\circ} \mathrm{C}$ (DH40i, Warner Instruments, Inc.). During the entire time-lapse session, the tissue was oxygenated using a mixture of $95 \% \mathrm{O}_{2} / 5 \%$ $\mathrm{CO}_{2}$. To prevent evaporation of the culture medium, the internal environment of the chamber was continuously humidified (Humidifying module warmer HMW-1, Warner Instruments, Inc.). Mosaic images of the entire RMS were re-constructed from individual frames $(x-, y-$ and $z$ axis), acquired every 20 minutes during a period of $3 \mathrm{~h}$. We used an inverted fluorescence microscope (Axioscope FS, Zeiss) equipped with a $20 \times$ long-distance objective (LD plan Neofluar, Zeiss). For analysis, a maximal projection of the different planes taken along the $\mathrm{z}$-axis was obtained for each time-lapse. Individual RMS neuroblasts could be identified and their trajectories were tracked using Metamorph (Molecular Devices). Two migration variables were analyzed, the speed and displacement along the $\mathrm{x}$-axis, corresponding to the tangential displacement in the RMS, provided that the rostro-caudal axis of the RMS was positioned parallel to the $x$-axis (Figure 3B,C). Delta $x$ $(\Delta \mathrm{x})$, the total displacement of a cell along the rostro-caudal axis of the RMS during an experimental session, was used as an index of the direction of migration in the RMSOB pathway.

\section{Statistical analysis}

All results are expressed as averages \pm standard error of the mean. Experiments involving the comparison of a control and an experimental group were analyzed using the Student's $t$-test. For multiple comparisons either one- or two-way ANOVA were used with the Tukey method as a post-hoc test; the use of each is detailed in the Results section. For multiple comparisons of the immunohistochemical data Kruskal-Wallis and MannWhitney methods were used; in these cases significance was evaluated based on the Bonferroni adjustment of $P$-values. Differences were considered significant for values of $P<0.05$. Distributions were compared using the Kolmogorov-Smirnov test in the R program [70].

\section{Additional material}

\begin{abstract}
Additional file 1: Figure S1. Immunohistochemical staining for doublecortin (DCX) and neuronal nuclei marker (NeuN) in 6-div organotypic cultures. (A) Low magnification image (10x) from a sagittal organotypic slice stained with DAPI (blue) depicting the cellular nuclei in the rostral migratory stream (RMS), as delimited by dashed lines. (B) DCX (green) and DAPI labeling in the RMS elbow area. Inset: approximate location of the area shown in (C). (C) High magnification detail of the RMS double stained for DCX and DAPI. (D) Low magnification image showing the distribution of NeuN-expressing cells (green) in the granule cell layer (GCL) and absence of positive cells in the RMS in a sagittal organotypic slice of the $\mathrm{OB}$. Outlined by dashed lines, the borders of the $O B$ and the accessory $O B$ are depicted for reference. (E) High magnification detail of the GCL region and OB RMS showing NeuNexpressing cells in the former and the cellular nuclei stained with DAPI. (F) Higher magnification detail of the OB RMS and GCL double stained for DAPI and NeuN. Scale bars: $250 \mu \mathrm{m}$ for (A,E), $200 \mu \mathrm{m}$ for (B,F), $20 \mu \mathrm{m}$ for (C), and $500 \mu \mathrm{m}$ for (D).
\end{abstract}

Additional file 2: Figure S2. Immunohistochemical staining for GABA and tyrosine hydroxylase $(\mathrm{TH})$ in 6-div organotypic cultures. $(\mathbf{A}, \mathbf{B})$ Photomicrograph showing GABAergic cells (green) and cellular nuclei costained with DAPI (blue) in the RMS (A), and in the GCL regions (B). (C) Photomicrograph showing the presence of $\mathrm{TH}$-positive cells (green) surrounding a glomerulus in the $\mathrm{OB}$, in an organotypic slice co-stained with DAPI. Inset: approximate location of the region magnified in (Ci). (Ci) High magnification photomicrograph showing a TH-positive cell costained with DAPI in an OB glomerulus. (D) Photomicrograph showing TH-expressing cells in the $\mathrm{OB}$ of an organotypic slice. Inset: approximate location of the region depicted in (Di). (Di) High magnification photomicrograph of a TH-expressing cell double labeled with DAPI in the OB. Scale bars: $50 \mu \mathrm{m}$ for (A), $20 \mu \mathrm{m}$ for (B), $100 \mu \mathrm{m}$ in (C,D), $20 \mu \mathrm{m}$ in $(\mathrm{Ci}, \mathrm{Di})$.

Additional file 3: Figure S3. Functional maturation of recorded GFP cells. (A) Scatter plot and linear regression analysis showing a lack of correlation between input membrane resistance (IR) and days postinjection (dpi) for neuroblasts migrating in the RMS. (B) A significant correlation was found in maturing GCs. Each point in the plot represents the values of one recorded GFP ${ }^{+}$cell.

Additional file 4: Figure S4. Immunohistochemical staining for NKCC1 in control and shNKCC1 neuroblasts and GCs. (A) Upper panel: photomicrograph showing the immunolabeling for NKCC1 (red) and GFP ${ }^{+}$(green) on migrating neuroblasts in the RMS transduced with the control non-target sequence. Lower panel: product of the differences from the mean (PDM) analysis for the double staining, as described for Figure 2. (Ai) Upper panel: photomicrograph showing the immunolabeling for NKCC1 (red) on GFP' (green) neuroblasts located in the RMS and transduced with the shNKCC1 sequence. Lower panel: PDM analysis for the upper panel image. (B) Upper panel: photomicrograph showing the immunolabeling for NKCC1 (red) and GFP (green) on GCs transduced with the control non-target sequence. Lower panel: PDM analysis for the double labeling. (Bi) Upper panel: photomicrograph showing the immunolabeling for NKCC1 (red) in $\mathrm{GFP}^{+}$(green) 
neuroblasts located in the GCL and transduced with the shNKCC sequence. Lower panel: PDM analysis for the upper panel image. For ( $A$, $A i, B, B i)$ scale bars are $10 \mu \mathrm{m}$. Photographs in $(A, A i)$ were taken from cultures fixed at $6 \mathrm{dpi}$ and in (B,Bi) at $7 \mathrm{dpi}$. (C) Normalized average $( \pm$ standard error of the mean) number of neuroblasts and GCs showing correlated NKCC1 and GFP signals in cells transduced with the control and shNKCC1 sequences.

Additional file 5: Video 1. Video showing the migration of neuroblasts transduced with the non-target control sequence in the RMS. The total duration of the session is 3 hours.

Additional file 6: Video 2. Video showing the migration of neuroblasts transduced with the shNKCC1 sequence in the RMS. The total duration of the session is 3 hours.

Additional file 7: Figure S5. Immunohistochemical staining for KCC2 in the organotypic slices 6 days after transduction with the shNKCC1- and GFP-encoding sequences. (A) Upper panel: photomicrograph of the RMS showing KCC2 immunostaining (red) in $\mathrm{GFP}^{+}$migrating neuroblasts (green). Lower panel: product of the differences from the mean (PDM) analysis for the immunostaining in (A), as explained in Figure 2. (B) Upper panel: photomicrograph showing KCC2 immunostaining (red) of $\mathrm{GFP}^{+}$maturing interneurons in the GCL. Lower panel: PDM analysis for the immunostaining in (B). Scale bars: $10 \mu \mathrm{m}$ in (A) and $20 \mu \mathrm{m}$ in (B).

Additional file 8: Figure S6. The reversal potential of $G A B A_{A}$-mediated responses in neuroblasts and GCs did not evolve in the culture. $(\mathbf{A}, \mathbf{B})$ Scatter plot and linear regression analysis showing the lack of correlation between the reversal potential for GABA and days post-injection (dpi) in neuroblasts migrating in the RMS (A) and in GCs (B). Each point in the plot represents the values of one recorded $\mathrm{GFP}^{+}$cell.

Additional file 9: Figure S7. Example traces showing the measurements of voltage-dependent $\mathrm{K}^{+}$current reversal in neuroblasts recorded in the cell attached configuration. Upper panel: three independent traces (gray) and their average (black) recorded in response to the voltage ramp depicted in the lower panel. (A,B) The blue dashed lines represent the linear fit applied to the average current trace and the black dashed lines indicate the corresponding voltage value for the reversal of $\mathrm{K}^{+}$voltagedependent currents in a control cell (A) and in a shNKCC1 cell (B). Scale bars: $100 \mathrm{pA}$ and $2 \mathrm{~ms}$ for (A) and $50 \mathrm{pA}$ and $2 \mathrm{~ms}$ for (B).

\section{Abbreviations}

ACSF: artificial cerebrospinal fluid; DCX: doublecortin; div: days in vitro; dpi: days post-injection; GABA: gamma-aminobutyric acid; GC: granule cell; GCL: granule cell layer; GFP: green fluorescent protein; IR: input membrane resistance; $\mathrm{KCC2}$ : $\mathrm{K}^{+}-\mathrm{Cl}^{-}$; $\mathrm{NKCC}$ : $\mathrm{Na}^{+}-\mathrm{K}^{+}-2 \mathrm{Cl}$; OB: olfactory bulb; $\mathrm{PBS}$ : phosphate-buffered saline; PGC: periglomerular cell; RMP: resting membrane potential; RMS: rostral migratory stream; shRNA: short hairpin RNA; SVZ: subventricular zone; TH: tyrosine hydroxylase.

\section{Acknowledgements}

This work was supported by the Fondation pour la Recherche Médicale ("Equipe FRM"), the Groupe Arpège, the Agence Nationale de la Recherche (ANR-2007-SEST-015 03), and the Ecole des Neurosciences de Paris (ENP). SM-G first held a fellowship from the ANR (ANR-05-Neur-028-01) and then a Pasteur-Weissman Fellowship. We thank E Avale and U Maskos (Institut Pasteur) for helping us to design the lentiviral vectors. We also thank A Marty (University Paris V) for useful comments on our manuscript and $G$ Gheusi (Institut Pasteur) for discussion on statistical analysis.

\section{Author details}

'Institut Pasteur, Laboratory for Perception and Memory, 25 rue du Dr. Roux, F-75724 Paris Cedex 15, France. ${ }^{2}$ Centre National de la Recherche Scientifique (CNRS) Unité de Recherche Associée (URA) 2182, 75724 Paris, France.

\section{Authors' contributions}

The experimental work of this study was achieved at the laboratory for Perception and Memory, at the Pasteur Institute in Paris. S-MG and PM-L conceived and designed the experiments. K-M produced the viral vectors, organotypic cultures, immunohistochemical staining and corrected the English in the manuscript. S-MG performed the electrophysiological and migration experiments as well as the data analysis and interpretation. S-MG and $P M-L$ wrote the manuscript.

\section{Competing interests}

The authors declare that they have no competing interests.

Received: 9 October 2010 Accepted: 1 February 2011 Published: 1 February 2011

\section{References}

1. Altman J: Autoradiographic and histological studies of postnatal neurogenesis. IV. Cell proliferation and migration in the anterior forebrain, with special reference to persisting neurogenesis in the olfactory bulb. J Comp Neurol 1969, 137:433-457.

2. Lledo PM, Alonso M, Grubb MS: Adult neurogenesis and functional plasticity in neuronal circuits. Nat Rev Neurosci 2006, 7:179-193.

3. Lois C, Alvarez-Buylla A: Long-distance neuronal migration in the adult mammalian brain. Science 1994, 264:1145-1148.

4. Luskin MB: Restricted proliferation and migration of postnatally generated neurons derived from the forebrain subventricular zone. Neuron 1993, 11:173-189.

5. $\mathrm{Hu} \mathrm{H}$, Rutishauser $\mathrm{U}$ : A septum-derived chemorepulsive factor for migrating olfactory interneuron precursors. Neuron 1996, 16:933-940.

6. Jankovski A, Sotelo C: Subventricular zone-olfactory bulb migratory pathway in the adult mouse: cellular composition and specificity as determined by heterochronic and heterotopic transplantation. J Comp Neurol 1996, 371:376-396.

7. Murase S, Horwitz AF: Deleted in colorectal carcinoma and differentially expressed integrins mediate the directional migration of neural precursors in the rostral migratory stream. J Neurosci 2002, 22:3568-3579.

8. Hagg T: Molecular regulation of adult CNS neurogenesis: an integrated view. Trends Neurosci 2005, 28:589-595.

9. Nguyen-Ba-Charvet KT, Picard-Riera N, Tessier-Lavigne M, Baron-Van Evercooren A, Sotelo C, Chedotal A: Multiple roles for slits in the control of cell migration in the rostral migratory stream. J Neurosci 2004, 24:1497-1506.

10. Bordey A: Enigmatic GABAergic networks in adult neurogenic zones. Brain Res Rev 2007, 53:124-134.

11. Ming GL, Song $H$ : Adult neurogenesis in the mammalian central nervous system. Annu Rev Neurosci 2005, 28:223-250.

12. Bolteus AJ, Bordey A: GABA release and uptake regulate neuronal precursor migration in the postnatal subventricular zone. J Neurosci 2004 24:7623-7631.

13. Wang DD, Krueger DD, Bordey A: GABA depolarizes neuronal progenitors of the postnatal subventricular zone via GABAA receptor activation. $J$ Physiol 2003, 550:785-800.

14. Ben-Ari Y, Cherubini E, Corradetti R, Gaiarsa JL: Giant synaptic potentials in immature rat CA3 hippocampal neurones. J Physiol 1989, 416:303-325.

15. Misgeld U, Deisz RA, Dodt HU, Lux HD: The role of chloride transport in postsynaptic inhibition of hippocampal neurons. Science 1986, 232:1413-1415.

16. Mueller AL, Taube JS, Schwartzkroin PA: Development of hyperpolarizing inhibitory postsynaptic potentials and hyperpolarizing response to gamma-aminobutyric acid in rabbit hippocampus studied in vitro. $J$ Neurosci 1984, 4:860-867.

17. Rivera C, Voipio J, Payne JA, Ruusuvuori E, Lahtinen H, Lamsa K, Pirvola U, Saarma M, Kaila K: The $\mathrm{K}+/ \mathrm{Cl}$ - co-transporter KCC2 renders GABA hyperpolarizing during neuronal maturation. Nature 1999, 397:251-255.

18. Owens DF, Boyce LH, Davis MB, Kriegstein AR: Excitatory GABA responses in embryonic and neonatal cortical slices demonstrated by gramicidin perforated-patch recordings and calcium imaging. J Neurosci 1996, 16:6414-6423.

19. Yamada J, Okabe A, Toyoda H, Kilb W, Luhmann HJ, Fukuda A: Cl- uptake promoting depolarizing GABA actions in immature rat neocortical neurones is mediated by NKCC1. J Physiol 2004, 557:829-841.

20. Delpy A, Allain AE, Meyrand P, Branchereau P: NKCC1 cotransporter inactivation underlies embryonic development of chloride-mediated inhibition in mouse spinal motoneuron. J Physiol 2008, 586:1059-1075. 
21. Ge S, Goh EL, Sailor KA, Kitabatake Y, Ming GL, Song H: GABA regulates synaptic integration of newly generated neurons in the adult brain. Nature 2006, 439:589-593.

22. Plotkin MD, Snyder EY, Hebert SC, Delpire E: Expression of the Na-K-2Cl cotransporter is developmentally regulated in postnatal rat brains: a possible mechanism underlying GABA's excitatory role in immature brain. J Neurobiol 1997, 33:781-795.

23. Wang DD, Kriegstein AR: GABA regulates excitatory synapse formation in the neocortex via NMDA receptor activation. J Neurosci 2008, 28:5547-5558

24. Ben-Ari Y: Excitatory actions of gaba during development: the nature of the nurture. Nat Rev Neurosci 2002, 3:728-739.

25. Gascon E, Dayer AG, Sauvain MO, Potter G, Jenny B, De Roo M, Zgraggen E, Demaurex N, Muller D, Kiss JZ: GABA regulates dendritic growth by stabilizing lamellipodia in newly generated interneurons of the olfactory bulb. J Neurosci 2006, 26:12956-12966.

26. Mejia-Gervacio S, Marty A: Control of interneurone firing pattern by axonal autoreceptors in the juvenile rat cerebellum. J Physio/ 2006, 571:43-55.

27. Obrietan K, van den Pol AN: Growth cone calcium elevation by GABA. $J$ Comp Neurol 1996, 372:167-175.

28. Alonso M, Ortega-Perez I, Grubb MS, Bourgeois JP, Charneau P, Lledo PM: Turning astrocytes from the rostral migratory stream into neurons: a role for the olfactory sensory organ. J Neurosci 2008, 28:11089-11102.

29. Imayoshi I, Sakamoto M, Ohtsuka T, Takao K, Miyakawa T, Yamaguchi M, Mori K, Ikeda T, Itohara S, Kageyama R: Roles of continuous neurogenesis in the structural and functional integrity of the adult forebrain. Nat Neurosci 2008, 11:1153-1161.

30. Kishi K: Golgi studies on the development of granule cells of the rat olfactory bulb with reference to migration in the subependymal layer. J Comp Neurol 1987, 258:112-124.

31. Carleton A, Petreanu LT, Lansford R, Alvarez-Buylla A, Lledo PM: Becoming a new neuron in the adult olfactory bulb. Nat Neurosci 2003, 6:507-518.

32. Payne JA, Rivera C, Voipio J, Kaila K: Cation-chloride co-transporters in neuronal communication, development and trauma. Trends Neurosci 2003, 26:199-206.

33. Russell JM: Sodium-potassium-chloride cotransport. Physiol Rev 2000, 80:211-276.

34. Jagasia R, Steib K, Englberger E, Herold S, Faus-Kessler T, Saxe M, Gage FH, Song $H$, Lie DC: GABA-cAMP response element-binding protein signaling regulates maturation and survival of newly generated neurons in the adult hippocampus. J Neurosci 2009, 29:7966-7977.

35. Ceccarelli B, Hurlbut WP: Ca2+-dependent recycling of synaptic vesicles at the frog neuromuscular junction. J Cell Biol 1980, 87:297-303.

36. Tzeng MC, Siekevitz P: The effect of the purified major protein factor (alpha-latrotoxin) of black widow spider venom on the release of acetylcholine and norepinephrine from mouse cerebral cortex slices. Brain Res 1978, 139:190-196.

37. Brickley SG, Cull-Candy SG, Farrant M: Development of a tonic form of synaptic inhibition in rat cerebellar granule cells resulting from persistent activation of GABAA receptors. J Physiol 1996, 497:753-759.

38. Verheugen JA, Fricker D, Miles R: Noninvasive measurements of the membrane potential and GABAergic action in hippocampal interneurons. J Neurosci 1999, 19:2546-2555.

39. Brumback AC, Staley KJ: Thermodynamic regulation of NKCC1-mediated $\mathrm{Cl}$ - cotransport underlies plasticity of $\mathrm{GABA}(\mathrm{A})$ signaling in neonatal neurons. J Neurosci 2008, 28:1301-1312.

40. Cancedda L, Fiumelli $\mathrm{H}$, Chen $\mathrm{K}$, Poo MM: Excitatory GABA action is essential for morphological maturation of cortical neurons in vivo. J Neurosci 2007, 27:5224-5235.

41. Sipila ST, Huttu K, Yamada J, Afzalov R, Voipio J, Blaesse P, Kaila K: Compensatory enhancement of intrinsic spiking upon NKCC1 disruption in neonatal hippocampus. J Neurosci 2009, 29:6982-6988.

42. Rakowski RF, Gadsby DC, De Weer P: Stoichiometry and voltage dependence of the sodium pump in voltage-clamped, internally dialyzed squid giant axon. J Gen Physiol 1989, 93:903-941.

43. Liu X, Wang Q, Haydar TF, Bordey A: Nonsynaptic GABA signaling in postnatal subventricular zone controls proliferation of GFAP-expressing progenitors. Nat Neurosci 2005, 8:1179-1187.
44. Platel JC, Heintz T, Young S, Gordon V, Bordey A: Tonic activation of GLUK5 kainate receptors decreases neuroblast migration in wholemounts of the subventricular zone. J Physiol 2008, 586:3783-3793.

45. Heck N, Kilb W, Reiprich P, Kubota H, Furukawa T, Fukuda A, Luhmann HJ: GABA-A receptors regulate neocortical neuronal migration in vitro and in vivo. Cereb Cortex 2007, 17:138-148.

46. Petreanu L, Alvarez-Buylla A: Maturation and death of adult-born olfactory bulb granule neurons: role of olfaction. J Neurosci 2002, 22:6106-6113.

47. Frazier-Cierpial L, Brunjes PC: Early postnatal cellular proliferation and survival in the olfactory bulb and rostral migratory stream of normal and unilaterally odor-deprived rats. J Comp Neurol 1989, 289:481-492.

48. Jankovski A, Garcia C, Soriano E, Sotelo C: Proliferation, migration and differentiation of neuronal progenitor cells in the adult mouse subventricular zone surgically separated from its olfactory bulb. Eur $J$ Neurosci 1998, 10:3853-3868.

49. Parent JM, Valentin $\mathrm{W}$, Lowenstein $\mathrm{DH}$ : Prolonged seizures increase proliferating neuroblasts in the adult rat subventricular zone-olfactory bulb pathway. I Neurosci 2002, 22:3174-3188.

50. Arvidsson A, Collin T, Kirik D, Kokaia Z, Lindvall O: Neuronal replacement from endogenous precursors in the adult brain after stroke. Nat Med 2002, 8:963-970.

51. Balena T, Woodin MA: Coincident pre- and postsynaptic activity downregulates NKCC1 to hyperpolarize $\mathrm{E}(\mathrm{Cl})$ during development. Eur J Neurosci 2008, 27:2402-2412.

52. Fiumelli H, Cancedda L, Poo MM: Modulation of GABAergic transmission by activity via postsynaptic Ca2+-dependent regulation of KCC2 function. Neuron 2005, 48:773-786.

53. Tanaka Y, Tozuka Y, Takata T, Shimazu N, Matsumura N, Ohta A, Hisatsune T: Excitatory GABAergic activation of cortical dividing glial cells. Cereb Cortex 2009, 19:2181-2195.

54. Akiba Y, Cave JW, Akiba N, Langley B, Ratan RR, Baker H: Histone deacetylase inhibitors de-repress tyrosine hydroxylase expression in the olfactory bulb and rostral migratory stream. Biochem Biophys Res Commun 2010, 393:673-677.

55. Schoppa NE: A novel local circuit in the olfactory bulb involving an old short-axon cell. Neuron 2006, 49:783-784.

56. Wang C, Ohno K, Furukawa T, Ueki T, Ikeda M, Fukuda A, Sato K: Differential expression of KCC2 accounts for the differential GABA responses between relay and intrinsic neurons in the early postnatal rat olfactory bulb. Eur J Neurosci 2005, 21:1449-1455.

57. Chavas J, Marty A: Coexistence of excitatory and inhibitory GABA synapses in the cerebellar interneuron network. J Neurosci 2003, 23:2019-2031.

58. Banke TG, McBain CJ: GABAergic input onto CA3 hippocampal interneurons remains shunting throughout development. J Neurosci 2006, 26:11720-11725.

59. Obata K: Transmitter sensitivities of some nerve and muscle cells in culture. Brain Res 1974, 73:71-88.

60. Blaesse $P$, Airaksinen MS, Rivera C, Kaila K: Cation-chloride cotransporters and neuronal function. Neuron 2009, 61:820-838.

61. Li H, Khirug S, Cai C, Ludwig A, Blaesse P, Kolikova J, Afzalov R, Coleman SK, Lauri S, Airaksinen MS, Keinänen K, Khiroug L, Saarma M, Kaila K, Rivera C: KCC2 interacts with the dendritic cytoskeleton to promote spine development. Neuron 2007, 56:1019-1033.

62. Belluzzi O, Benedusi M, Ackman J, LoTurco JJ: Electrophysiological differentiation of new neurons in the olfactory bulb. J Neurosci 2003, 23:10411-10418.

63. Stewart RR, Hoge GJ, Zigova T, Luskin MB: Neural progenitor cells of the neonatal rat anterior subventricular zone express functional GABA(A) receptors. J Neurobiol 2002, 50:305-322.

64. Stoppini L, Buchs PA, Muller D: A simple method for organotypic cultures of nervous tissue. J Neurosci Methods 1991, 37:173-182.

65. Avale ME, Faure P, Pons S, Robledo P, Deltheil T, David DJ, Gardier AM, Maldonado R, Granon S, Changeux JP, Maskos U: Interplay of beta2* nicotinic receptors and dopamine pathways in the control of spontaneous locomotion. Proc Natl Acad Sci USA 2008, 105:15991-15996.

66. Kyrozis A, Reichling DB: Perforated-patch recording with gramicidin avoids artifactual changes in intracellular chloride concentration. J Neurosci Methods 1995, 57:27-35. 
67. Ehrlich I, Lohrke S, Friauf E: Shift from depolarizing to hyperpolarizing glycine action in rat auditory neurones is due to age-dependent $\mathrm{Cl}$ regulation. J Physiol 1999, 520:121-137.

68. Khawaled R, Bruening-Wright A, Adelman JP, Maylie J: Bicuculline block of small-conductance calcium-activated potassium channels. Pflugers Arch 1999, 438:314-321.

69. Li Q, Lau A, Morris TJ, Guo L, Fordyce CB, Stanley EF: A syntaxin 1, Galpha (o), and $\mathrm{N}$-type calcium channel complex at a presynaptic nerve terminal: analysis by quantitative immunocolocalization. J Neurosci 2004 24:4070-4081

70. The R Project for Statistical Computing. [http://www.r-project.org/].

doi:10.1186/1749-8104-6-4

Cite this article as: Mejia-Gervacio et al:: NKCC1 controls GABAergic

signaling and neuroblast migration in the postnatal forebrain. Neura

Development 2011 6:4.

\section{Submit your next manuscript to BioMed Central} and take full advantage of:

- Convenient online submission

- Thorough peer review

- No space constraints or color figure charges

- Immediate publication on acceptance

- Inclusion in PubMed, CAS, Scopus and Google Scholar

- Research which is freely available for redistribution

Submit your manuscript at www.biomedcentral.com/submit 